\title{
Acat1 gene KO restores TGN cholesterol deficiency in mutant NPC1 cells and expands mutant Npc1 mouse lifespan
}

Maximillian A. Rogers ${ }^{2,6}$, Catherine C.Y. Chang ${ }^{1,6, *}$, Robert A. Maue ${ }^{1,3}$, Huang ${ }^{1}$, Peter W. Schroen ${ }^{1}$, and Ta-Yuan Chang ${ }^{1, *},{ }^{, *}$

$9{ }^{1}$ Department of Biochemistry and Cell Biology, Geisel School of Medicine at Dartmouth,

10 Hanover, NH 03755 USA.

$11{ }^{2}$ Center for Interdisciplinary Cardiovascular Sciences, Cardiovascular Division, Brigham and

12 Women's Hospital, Harvard Medical School, Boston, MA, USA.

13 '3epartment of Medical Education, Geisel School of Medicine at Dartmouth College, Hanover,

$14 \mathrm{NH} 03755$ USA

$15{ }^{4}$ Department of Biomedical Science, Centre for Membrane Interactions and Dynamics,

16 University of Sheffield, Firth Court, Sheffield, S10 2TN, UK

$17{ }^{5}$ Department of Chemistry \& Chemical Biology, University of New Mexico,

18 Albuquerque, NM, 87131 USA

$19{ }^{6}$ Co-first author

20 “Correspondence: ta.yuan.chang@dartmouth.edu; catherine.chang@dartmouth.edu

$21{ }^{* *}$ Lead Contact: ta.yuan.chang@dartmouth.edu 


\section{Abstract}

24 Niemann-Pick type C (NPC) is a neurological disorder with no cure. NPC proteins deliver

25 cholesterol from endosomes to other compartments including trans-Golgi network (TGN) and

26 endoplasmic reticulum (ER). Acyl-coenzyme A:cholesterol acyltransferase 1 (ACAT1) is a

27 resident ER enzyme that converts cholesterol to cholesteryl esters for storage. Here, we report

28 the surprising finding that in a mutant Npc1 mice, Acat1-deficiency delayed the onset of weight

29 loss and declining motor skill, prolonged lifespan, delayed Purkinje neuron death, and improved

30 hepatosplenic pathology. Furthermore, syntaxin 6, a cholesterol-binding t-SNARE normally

31 localized to TGN, is mislocalized in mutant NPC cells. However, upon ACAT1 inhibition this

32 mislocalization is corrected, and increase the level of a few proteins further downstream. Our

33 results imply that ACAT1 inhibition diverts a cholesterol storage pool in a way that replenished

34 the low cholesterol level in NPC-deficient TGN. Taking together, we identify ACAT1 inhibition as

35 a potential therapeutic target for NPC treatment. 


\section{Introduction}

Niemann-Pick disease type $\mathrm{C}$ (NPC) is a genetically recessive neurodegenerative disease caused by mutations in Npc1 (1), (2) or in Npc2 (3). Loss of in NPC1 or NPC2 function results in the accumulation of cholesterol (4) as well as various sphingolipid species (5), mainly within late endosomes/lysosomes (LE/LYS). NPC disease shares many similar attributes with Alzheimer's disease, and is colloquially referred to as juvenile Alzheimer's disease. As such any mechanistic and therapeutic findings in NPC disease may have broad application to other neurodegenerative diseases. The lipid accumulation seen in NPC occurs in all tissues, and results in neurodegeneration as well as malfunctions in liver and lung. In brain, the most extensive cell death occurs in cerebellum, with preferential loss of Purkinje neurons. In terms of potential therapies, migluostat, a glycosphingolipid synthesis inhibitor, has demonstrated significant efficacy (6). However, migluostat is not FDA-approved as an NPC therapy. Intrathecal delivery of 2-hydroxypropyl- $\beta$-cyclodextrin, a water-soluble molecule that binds cholesterol, reduces neurological disease progression (7), (8), but the clinical benefit of cyclodextrin has yet to be clearly demonstrated in ameliorating the disease pathology in NPC1 patients. Given the current lack of approved NPC treatments, there remains a critical need to develop therapeutic approaches for the treatment of NPC disease.

Cholesterol is an essential lipid molecule needed for cell growth and function. Cells acquire cholesterol through exogenous sources as well as through de novo biosynthesis. Exogenous cholesterol enters cells mainly through receptor-mediated endocytosis. Subsequently, it is distributed to various membrane compartments for utilization, feed-back regulation of cholesterol metabolism, and storage as cytoplasmic cholesteryl ester lipid droplets [Reviewed in (9)]. Distribution of cholesterol from the LE/LYS to other membrane compartments requires NPC1 and NPC2. Both NPC1 and NPC2 bind to cholesterol (10), (11), (12), (13). These two proteins work in concert to export cholesterol from LE to other membrane organelles [reviewed in (14)]. In cells with NPC mutations, buildup of cholesterol and other lipids occurs within LE/LYS, while leaving other membrane compartments, including plasma membrane (PM) (15),

71 (16), endoplasmic reticulum (ER) (17), (18), (19), (20), peroxisomes (21), and trans-Golgi

72 network (TGN) (22), (23) relatively deficient in cholesterol. In mutant NPC cells, abnormal

73 membrane cholesterol distribution cause malfunctions in LE/LYS (24), and in other membrane

74 organelles (23), (25). Cholesterol overload in LE/LYS also causes cholesterol accumulation in

75 the inner membranes of mitochondria (26), (27), (28), (29). 
In addition to receiving cholesterol from exogenous uptake, cells produce cholesterol from de novo biosynthesis. Upon synthesis at the ER, sterols quickly move to the PM within a few minutes, via mechanisms independent of NPC1 (30). Cholesterol from both endogenous and exogenous sources traverse among various membrane compartments [reviewed in (31), (32)].

80 To prevent overaccumulation of free cholesterol in cells, which would result in cellular toxicity

81 [reviewed in (33), acyl-coenzyme A:cholesterol acyltransferase 1 (ACAT1) (also called sterol O-

82 acyltransferase 1 [SOAT1]) (34), converts a certain portion of cellular cholesterol to cholesterol

83 esters. Furthermore, ATP binding cassette transporter A1 (ABCA1) [reviewed in (35)].

84 removes excess cholesterol through a lipid efflux process.

ACAT1 is a membrane protein residing at the ER (36); in addition, a certain portion of ACAT1 is found close to other cellular organelles including PM (37), recycling endosomes, (38), and TGN (39). In mutant NPC cells, the absence of functional NPC1 or NPC2 considerably slows delivery of cholesterol from LE/LYS to ER; however, a significant amount of cholesterol can translocate from the PM to the ER for esterification in an NPC-independent manner (16, 40-43), $(44,45)$. Here, we hypothesize that in mutant NPC cells, ACAT1 inhibition causes the NPC-independent cholesterol pool arriving at ER to build up. Once built-up, this cholesterol pool moves away from ER to other subcellular membrane compartments, including TGN, to fulfill their needs for cholesterol. To test this hypothesis, we adopted a transgenic mouse model-based approach.

A mutant mouse model for NPC disease $\left(N p c 1^{n m f}\right.$ mouse) was discovered and characterized by Maue et al. (46). This $N p c 1^{n m f}$ mouse model has a C57BL/6J genetic background, and a single D1005G-Npc1 mutation located within the cysteine-rich luminal loop of the NPC1 protein; which is comparable to mutations that commonly occur in human Npc1 patients. Homozygous $N p c 1^{n m f / n m f}$ mice begin to die by 90 days (almost 13 weeks) after birth; and exhibit a phenotype

101 that mimics the late onset, slowly progressing form of NPC disease. In contrast, heterozygous

$102 \mathrm{Npc1^{nmf/+ }}$ mice seem to exhibit a generally normal mouse phenotype and are fertile. In the

103 studies presented here, we bred heterozygous $N p c 1^{n m f /+}$ mice with global $A c a t 1^{-/-}\left(A 1^{-/}\right)$-deficient 104 mice (47), which also have a C57BL/6J genetic background, to produce $N p c 1^{n m f / n m f}: A 1^{+/+}$and

$105 N p c 1^{n m f / n m f}: A 1^{-/}$mice. We then performed paired studies in vivo by using sex and age matched $106 N p c 1^{n m f / n m f}: A 1^{+/+}\left(N p c 1^{n m f}\right)$ and $N p c 1^{n m f / n m f}: A 1^{-/}$mice $\left(N p c 1^{n m f}: A 1^{-/}\right)$. We used littermates from

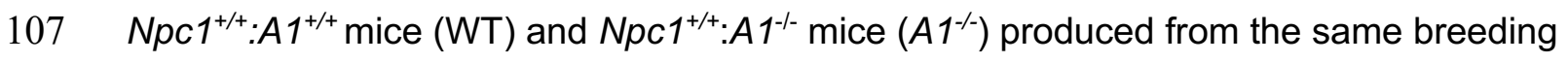
108 experiments as non-diseased controls. In addition, we isolated embryonic fibroblast cells from $109 N p c 1^{n m f}, N p c 1^{n m f}: A 1^{-/}, \mathrm{WT}$, and $A 1^{-/}$mice to perform paired studies in vitro in primary cell 
110 culture. Furthermore, to evaluate the relevance of our findings in the context of human disease, 111 we monitored the effect of a small molecule ACAT1-specific inhibitor K604 on human fibroblast 112 (Hfs) cells isolated from several patients with NPC disease as well as on a human fibroblast 113 cells isolated from a patient with a related lysosomal storage disease Niemann-Pick type A 114 (NPA). The results of both these in vivo and in vitro approaches are reported here.

115

116 


\section{Results}

Acat1 gene deficiency $\left(A 1^{-/}\right)$increased life span and reduced weight loss in $N p c 1^{n m f}$ mice.

120 To evaluate effects of $A 1^{-/}$on lifespan of homozygous $N p c 1^{n m f}$ mice, mice with four genotypes

$121\left(\mathrm{WT}, A 1^{-/}, N p c 1^{n m f}\right.$, and $\left.N p c 1^{n m f}: A 1^{-/}\right)$were fed a regular chow diet and their lifespans were 122 assessed. The age of death for $N p c 1^{n m f}$ mice with or without $A 1$ were determined as the point 123 where mice could no longer take in food or water, as described previously (46). Results (Fig. 124 1A) show that the median survival for $N p c 1^{n m f}$ and $N p c 1^{n m f}: A 1^{-/-}$mice is 113 days and 138 days 125 respectively, with the mean survival being 102 days and 137 days, respectively.

Overall, $A 1^{-/-}$increased $N p c 1^{n m f}$ mutant mouse lifespan by $34 \%$. In control experiments, no spontaneous deaths occurred in either WT mice or $A 1^{-1-}$ mice. We next evaluated the effect of A1-deficiency on the weights of $N p c 1^{n m f}$ mice, starting at 6 weeks of age. Results (Fig. 1B; right hand panel) show that $N p c 1^{n m f}$ mice start to lose weight at around 9 weeks of age. In contrast, mice lacking $A 1$ gene did not begin to lose weight until 13 weeks of age. Thus, the lack of $A 1$ delayed the onset of weight loss observed in $N p c 1^{n m f}$ mice. In control experiments (Fig. 1B; left hand panel) at 6 weeks of age, $A 1^{-/-}$mice weighed slightly less than WT mice, but at 8 weeks of age or older, the difference in weights between these 2 genotypes disappeared.

\section{$A 1^{-/-}$reduced foam cell pathology in liver/spleen and Purkinje neuron loss in Npc1 ${ }^{\text {nmf }}$}

137 mice. Niemann-Pick disease exhibits accumulation of large foamy macrophages in various

138 tissues. To determine if Acat1 inhibition had any effect on the foam cell pathology in Npc1 ${ }^{\text {nmf }}$

139 mouse, we isolated tissues from WT, $A 1^{-/-}, N p c 1^{n m f}$, and $N p c 1^{n m f}: A 1^{-/-}$mice at 80 days (P80) of

140 age, and performed histological staining analyses. When compared to $N p c 1^{n m f}$ mice,

$141 N p c 1^{n m f}: A 1^{-/-}$mice have significantly reduced foam cell pathology in liver (Fig. 2A; right panels;

142 top vs. bottom) and spleen (Fig. 2B; right panels; top vs. bottom). In lung, however, foam

143 cell pathology in these two genotypes are comparable (Fig. 2C; right panels; top vs. bottom).

144 The result of the control experiments confirmed that neither WT mice nor global $A 1^{-/-}$mice

145 exhibit significant foam cell pathology in any of these three tissues (Fig. 2A-C; left panel; top

146 vs. bottom). Previous studies in mutant NPC animals have demonstrated that extensive

147 Purkinje neuron cell death occurs prior to the death of the animals. To evaluate the effect of $A 1^{-1-}$

148 on Npc $^{\text {nmf }}$ Purkinje neurons, cerebellum was isolated from P80 mice brain, and the number of

149 Purkinje neurons were counted after histochemical staining of thin slices. As shown in Fig. 2D,

150 when compared to values that found in WT mice and in $A 1^{-/-}$mice, $N p c 1^{n m f}$ mice had less than 
$15120 \%$ residual Purkinje cells remaining, while in the $N p c 1^{n m f}: A 1^{-/-}$mice, the numbers of residual

152 Purkinje neurons remaining was more than $30 \%$ of WT values (Fig. 2D; right panels). To

153 validate the results shown in Fig. 2D, we isolated cerebellar tissue from the brains of P50 and

154 P90 mice, and compared the levels of calbindin mRNA, as calbindin expression is specific to

155 Purkinje neurons in the cerebellum. The results of P50 cerebellum (Fig. 2E; A), calbindin mRNA

156 levels in WT and $A 1^{-/-}$mice were comparable (first 2 bars on left). In $N p c 1^{\text {nmf }}$ mice (the $3^{\text {rd }}$ bar

157 from left), the expression was significantly reduced by $55 \%$ of the values found in WT and $A 1^{-/-}$

158 mice, but the expression was almost completely restored in $N p c 1^{\text {nmf }}: A 1^{-/}$mice $\left(4^{\text {th }}\right.$ bar from left)

159 to about $90 \%$ of values found in WT and $A 1^{-1 /}$ mice. The results obtained from the P90

160 cerebellum (Fig. 2E; B) show that calbindin expression in $N p c 1^{n m f}$ mice was drastically reduced

161 to about $10 \%$ of values found in WT and $A 1^{-/-}$mice, but was partially restored in $N p c 1^{n m f}: A 1^{-/}$

162 mice, to about $30 \%$ of values found in WT and $A 1^{-/-}$mice. Overall, these results demonstrate

163 that in the $N p c 1^{n m f}$ mouse model, $A 1$ gene ablation significantly decreases the loss of Purkinje

164 neurons in brain.

$A 1^{-/-}$ameliorated the motor deficits and behavior of $\mathrm{Npc} 1^{\mathrm{nmf}}$ mice. Mutant $N p c 1^{\mathrm{nmf}}$ mice exhibit a decline in their motor performance, beginning at 11 weeks of age (46). We monitored the motor performance of WT, $A 1^{--}, N p c 1^{n m f}$, and $N p c 1^{n m f}: A 1^{-/-}$mice beginning at 9 weeks of age by using a rotarod test. The results show that for $N p c 1^{n m f}$ mice, the mean age of failing off or not running on the rotarod test occurred at around 12 weeks of age, whereas for $N p c 1^{n m f}: A 1^{-/-}$mice, the mean age of failing occurred at 18 weeks of age (Fig. 2F). Results from control experiments show that at the same age, neither WT mice nor $A 1^{-/-}$mice fail the rotarod test. Since the rotarod test does not assess muscle strength per se, these results do demonstrate that $A 1$ gene ablation improves sensorimotor coordination and behavior in the $N p c 1^{n m f}$ mice. embryonic fibroblasts (MEF) from WT, $A 1^{-/}, \mathrm{Npc}^{\mathrm{nmf}}$, and $\mathrm{Npc}{ }^{\mathrm{nmf}}: \mathrm{A} 1^{-/}$mice. To determine

178 whether $A 1^{-/}$alters the total free cholesterol content in $N p c 1^{n m f}$ mouse brain, we first isolated 179 whole brains from WT, $A 1^{-/}, N p c 1^{n m f}$, and $N p c 1^{n m f}: A 1^{-/-}$mice at postnatal day 90 (P90) and

180 measured their total free (unesterified) cholesterol content. The results show that the cholesterol 181 content in these samples are comparable to one another (Fig. 3A).

183 In the central nervous system, however, the bulk of cholesterol exists in the membranes of a 184 variety of cell types, including the glial-derived myelin sheath, making measurements of bulk 
185 cholesterol less informative when considering the effects of NPC1 deficiency, as well as the

186 effects of ACAT1 inhibition on membrane cholesterol distribution at the cellular level. Parallel

187 cultures of primary fibroblasts isolated from normal mice and from mice with single mutations

188 have been used extensively as a model system to investigate the effects of single-gene

189 mutations at the biochemical level. We therefore used mouse embryonic fibroblasts (MEFs) to

190 address this question. We isolated MEFs from WT, $A 1^{-/}, N p c 1^{n m f}$, and $N p c 1^{n m f}: A 1^{-/}$mice, grew

191 them in DMEM with 10\% serum in monolayers until confluent, and then harvested the cells for

192 the analysis of total free cholesterol content. Results (Fig. 3B) show that the free cholesterol

193 content in these four cell types are very similar, demonstrating that under the condition

194 employed, neither NPC1 mutation nor ACAT1 blockage significantly affects the total cellular free

195 cholesterol content.

197 We next measured relative cholesterol ester biosynthesis rates in these cells by feeding labelled

$198{ }^{3} \mathrm{H}$-oleate to the intact cells for 20 -min and then measuring the ${ }^{3} \mathrm{H}$-cholesteryl oleate that was

199 produced. The results (Fig. 3C) show that when grown in lipoprotein-containing medium (10\%

200 serum), WT cells exhibit an ample cholesterol ester biosynthesis rate. As expected, in cells 201 without ACAT1 (i.e., $A 1^{-/}$cells and $N p c 1^{n m f}: A 1^{-/}$cells), the cholesterol ester biosynthesis rate 202 was only $2 \%$ that of WT cells. The residual amount of cholesteryl oleate in ACAT-deficient cells 203 formed are perhaps due to the presence of ACAT2 (48). In NpC1 ${ }^{n m f}$ cells, the rate was around

$20434 \%$ that of WT cells (Fig. 3C). When these four cell types were grown in 10\% delipidated 205 serum medium (i.e., medium devoid of exogenous cholesterol), the cholesteryl ester

206 biosynthesis rate in WT cells decreased drastically; these decreases also occurred in the other 207 three cell types (Fig. 3D; lanes 5-8); whereas, in contrast, when low-density lipoproteins (LDL) 208 were added to the delipidated serum (DLS) medium for $3 \mathrm{~h}, 6 \mathrm{~h}$, or for $24 \mathrm{~h}$ (indicated as LDL (3 209 h), LDL (6 h) or LDL (24 h) below the X-axis in Fig. 3D), cholesteryl ester biosynthesis rate was 210 restored in WT cells in a time-dependent manner. Adding LDL also increased cholesteryl ester

211 biosynthesis rate in mutant $N p c 1^{n m f}$ cells, but this increase was not nearly as what was observed 212 in WT cells (Fig. 3D; comparing $3^{\text {rd }}$ bars vs. $\mathbf{1}^{\text {st }}$ bars). These results show that within the $3-6 \mathrm{~h}$ 213 period, mutant $N p c 1^{n m f}$ cells fail to efficiently utilize LDL-derived cholesterol for esterification,

214 indicating the importance of NPC1 in delivering cholesterol from endosomes to the ER. As 215 expected, in $A 1^{-/}$cells or in $N p c 1^{n m f}: A 1^{-/}$cells, within the 3-6 $\mathrm{h}$ time frame, the LDL-dependent 216 increase in cholesterol ester biosynthesis rate was abolished (Fig. 3D; comparing $2^{\text {nd }}$ bars 217 and $4^{\text {th }}$ bars vs. the $\mathbf{1}^{\text {st }}$ bars). When cells were exposed to LDL for $24 \mathrm{~h}$, a large increase in 218 cholesterol ester biosynthesis rate occurred in $N p c 1^{n m f}$ cells but not in cells without $A 1$ (Fig. 3D; 
219 comparing last 4 bars at the LDL (24 h) time point). Our earlier results (Fig. 3C) show that,

220 when maintained in the lipoprotein- containing medium at a steady state, $N p c 1^{n m f}$ cells exhibit a

221 residual cholesterol ester biosynthesis rate of about $34 \%$ compared to WT cells. These results

222 support the notion (described in the Introduction) that, in addition to using cholesterol derived

223 from the NPC-containing late endosomes for esterification, cells can also use other cholesterol

224 sources for esterification at the ER, in an NPC-independent manner.

ACAT1 plays a key role in cholesterol storage via its conversion of cholesterol to cholesterol esters. In both WT and Npc1 ${ }^{n m f}$ MEFs, preventing cholesterol storage by inhibiting ACAT1 may cause significant alteration(s) in cholesterol distribution among various membrane organelles. To test this possibility, we performed intact cell staining with filipin, a naturally fluorescent small molecule that binds to cholesterol, and then viewed the labeled cells with spinning disc confocal fluorescence microscopy. The results show that in WT and $A 1^{-/}$cells (Fig. 4A; $\mathbf{1}^{\text {st }}$ and $2^{\text {nd }}$ columns), the cholesterol-rich domains, as represented by areas with strong filipin staining ( $1^{\text {st }}$ row), were mostly located in peripheral regions of the cytosol, whereas in mutant $N p c 1^{n m f}$ cells (Fig. 4A; $3^{\text {rd }}$ column), the cholesterol-rich domains were primarily peri-nuclear in their localization. It was previously shown that LE/LYS exhibit non-random, bidirectional movements between the nucleus region and the cell surface; when mutant NPC1 cells were laden with cholesterol and other lipids, the movements of LE/LYS towards the cell periphery became sluggish, presenting cholesterol-rich particles primarily to the perinuclear location (49). The results shown in Fig. 4A; $3^{\text {rd }}$ row confirms these findings. Importantly, in mutant $N p c 1^{\text {nmf }}$ cells, $A 1^{-/}$caused most of the cholesterol-rich particles to become primarily peripherally located (Fig. $4 A$; the $4^{\text {th }}$ column). We also calculated total cell fluorescence intensity of filipin per cell and found that the values among these four cell types were comparable (Fig. 4B). Overall, these results imply that $A 1^{-/}$corrected the late endo/lysosomal cholesterol sequestration defects seen in the mutant NPC1 cells without significantly altering the total cholesterol content in these cells. We also noted that when compared to WT cells, $A 1^{-1-}$ cells contained more cholesterol-rich

246 domains that are scattered throughout the cytoplasm (Fig. 4A; the $2^{\text {nd }}$ column), suggesting that

247 in WT cells, $A 1^{-/-}$causes significant cholesterol accumulation in certain internal membrane

248 organelle(s). The nature of these cholesterol-rich internal organelles is unknown at present.

250 To examine the membrane cholesterol distribution in these four cell types with another method, 251 we took a biochemical approach, and performed subcellular fractionation of post-nuclear cell 252 homogenates prepared from the MEFs of these four different genotypes, using OptiPrep density 
253 gradient ultracentrifugation. This method produces partial separation of various membrane

254 organelles, based primarily on their buoyant densities (50), (51), (22). After OptiPrep

255 fractionation we analyzed the distribution of various membrane organelles in the fractions by

256 performing Western blot analyses of protein markers for LE/LYS, TGN, ER, caveolae, and

257 mitochondria (Fig. 4C). We also analyzed cholesterol content in each fraction (Fig. 4D).

258 Western analyses (Fig. 4C) show that in all four cell types, LE/LYS (LAMP1 positive) were

259 tightly enriched in fractions \#1 to \#3 (with light density) and the mitochondria (cytochrome C

260 oxidase positive) were tightly enriched in fractions \#9 to \#11 (with heavy density). Mutant

$261 N p c 1^{n m f}$ cells, but not $N p c 1^{n m f}: A 1^{-/-}$cells, exhibited additional LAMP1 positive signals in fractions

262 \#5 to \#9. The ER (calnexin positive) exhibited a broader range of densities but was similarly

263 enriched in \#6 to \#10 in all cell types. The PM (caveolin 1 positive) was enriched in fractions \#5

264 to \#8 in WT cells (with medium density), but in $A 1^{-/}$cells was enriched in later fractions (\#7 to

265 \#9). This result suggests that $A 1^{-/-}$may cause an increase in buoyant density of the PM. Similar

266 to the WT cells, in mutant $N p c 1^{n m f}$ cells and in $N p c 1^{n m f}: A 1^{-/-}$cells, the PM were enriched in

267 fractions \#5 to \#8. However, the PM in mutant $N p c 1^{n m f}: A 1^{-1-}$ cells exhibited a broader range in

268 buoyant densities. These results show that except for the PM in $A 1^{-/-}$cells and the abnormal

269 LAMP1 positive signal in mutant $N p c 1^{n m f}$ cells, the buoyant densities of LE/LYS, mitochondria,

$270 \mathrm{ER}$, and PMs in these four cell types are comparable. In contrast, the syntaxin 6 rich-fractions

271 (Fig. 4C; $2^{\text {nd }}$ row) exhibited large variation in densities: in WT cells, they are enriched in

272 fractions \#5 to \#6; in $A 1^{-/-}$cells, in fractions \#8 to \#10; in Npc1 ${ }^{n m f}$ cells, in fractions \#8 to \#11, in

$273 N p c 1^{n m f}: A 1^{-1-}$ cells, in fractions \#5 to \#9. The results of cholesterol content analyses in the

274 OptiPrep fractions (Fig. 4D) show that as expected, in WT cells, cholesterol was highly enriched

275 in the PM fraction (\#5 to \#8), and membranes with slightly heavier densities, including the ER

276 membranes (\#7 to \#9), whereas the mitochondrial membranes had much less cholesterol

277 content. In $A 1^{-/-}$cells, membranes with heavier densities, including the ER (\#7 to \#9) and

278 mitochondria (\#9 to \#11), may be enriched in cholesterol. However, this interpretation is not

279 definitive, because in the $A 1^{-/}$cells, the PM fractions increased in buoyant densities, such that

280 they overlapped significantly with the ER fractions (\#7 to \#9) (Fig. 4C; $\mathbf{4}^{\text {th }}$ row). In mutant

$281 N p c 1^{n m f}$ cells, as expected, cholesterol was highly enriched in the light density late

282 endo/lysosomes (LE/LYS) fraction (fractions \#1 to \#3). In the mutant $N p c 1^{n m f}: A 1^{-/}$cells, the

283 Golgi-like membranes (\#6 to \#9), the PM-like membranes (\#5 to \#8), and the ER-like

284 membranes (\#7 to \#9), all become relatively enriched in cholesterol. These results corroborate

285 with the cholesterol distribution in intact cells (shown in Fig. 4A), and support the interpretation

286 that while in Npc1 $1^{n m f}$ cells cholesterol is mostly sequestered within LE/LYS, with the deletion of 
287 the $A 1$ gene in $N p c 1^{n m f}: A 1^{-/}$cells most of the sequestered cholesterols appears redistributed to 288 various other membrane organelles, including Golgi, ER, PM, and mitochondria.

\section{Effects of $A 1^{-/}$on syntaxin 6 and golgin 97 localization in intact mutant $N p c 1^{n m f}$ MEFs.}

291 The result presented in Fig. 4C ( $2^{\text {nd }}$ row) showed that the syntaxin 6-rich membranes isolated

292 from the four different MEFs exhibited large variation in buoyant densities. Syntaxin 6 binds to

293 cholesterol (52), and is one of the t-SNARE proteins present in vesicles that participate in

294 various membrane fusion events. The syntaxin 6-rich vesicles move dynamically between

295 various membrane organelles. In normal cells, most of the syntaxin 6 signal is found at the

296 TGN (53). The TGN is rich in cholesterol content (54), and plays key roles in transporting

297 proteins and lipids to various other membrane compartments, including the PMs and

298 endosomes. In mutant NPC cells, the TGN fails to receive LDL-derived cholesterol from the late

299 endosomes (22). This deficiency causes syntaxin 6 to be mislocalized from the TGN, and

300 instead it exhibits an abnormal, scattered cytoplasmic pattern (25). Importantly, treating mutant

301 NPC1 cells with cholesterol/cyclodextrin complex, or with high concentration of LDL for $24 \mathrm{~h}$

302 restores the syntaxin 6 signal to the typically one-sided, perinuclear Golgi localization pattern

303 observed in normal cells (25). In mutant NPC cells, other SNARE proteins such as syntaxin 16,

304 VAMP3, VAMP4, do not show cholesterol-sensitive localization patterns (25). Based on these

305 previous findings, as well as results presented in Fig. 4B,C,D, we postulated that $A 1^{-/}$may

306 correct the mis-localization pattern of syntaxin 6 observed in mutant $N p c 1^{n m f}$ MEFs. To test this

307 possibility, we performed immunofluorescence confocal microscopy in fixed, intact cells using

308 antibodies specific for syntaxin 6. The results (Fig. 5A) show that, in WT cells and in $A 1^{-/}$cells

309 most of the syntaxin 6 signal was highly polarized to only one side of the space adjacent to the

310 nucleus. This pattern is a typical Golgi distribution pattern found in mammalian cells (55). In

311 contrast, in mutant $N p c 1^{n m f}$ cells (Fig 5A), a significant portion of the syntaxin 6 signal was

312 distributed in scattered cytoplasmic vesicular structures; these structures were located at the

313 space around both sides of the nucleus. This result confirms the findings by Reverter et al. (25).

314 Importantly, $\mathrm{A} 1$ deletion $\left(A 1^{-/}\right)$in mutant NPC cells (Fig 5A) largely restored the syntaxin 6

315 distribution pattern back to the one-sided, peri-nuclear pattern observed in WT and $A 1^{-/}$cells. To

316 quantitate the difference of syntaxin 6 positive signals observed in the MEFs of these four

317 different genotypes, we adopted the procedure developed by Mitchel et al. (55), by measuring

318 the "Reflex angle", defined as the angle subtended by the edges of the syntaxin 6-positive

319 signals in the confocal images, using the center of the nucleus (DAPI positive signal) as the

320 vertex. The results (Fig. 5B) show that for WT and $A 1^{-/}$cells, the reflex angle was very similar : 
$321119^{\circ}$ or $126^{\circ}$ respectively; for mutant $N p c 1^{n m f}$ cells, the reflex angle was much larger $\left(346^{\circ}\right)$. For 322 mutant $N p c 1^{n m f}: A 1^{-/-}$cells, the reflex angle was largely restored, to $160^{\circ}$.

324 The results of control experiments (Fig. 5C) show that the level of syntaxin 6 protein in all four 325 cell types examined were comparable. Together, these results show that $A 1^{-/}$largely restores 326 the mis-localization of syntaxin 6 observed in mutant $N p c 1^{n m f}$ cells, without affecting the syntaxin 3276 protein content.

328 To strengthen these results, we sought to examine the localization pattern of a second protein 329 marker of the TGN. Golgins are long coiled-coil peripheral membrane proteins located mainly at 330 the membrane surface of the TGN (56). In humans there are four golgins, each playing a 331 distinct role in membrane protein transport events. Using specific antibodies against golgin 97

332 (GCC97), we performed double immunofluorescence experiments to compare the localization 333 patterns of syntaxin 6 and golgin 97 in parallel cultures of four MEF cell types. The results show 334 that, in WT cells (Fig. 5D, $1^{\text {st }}$ row), golgin 97 exhibited a typical polarized Golgi distribution pattern. In $A 1^{-/}$cells (Fig. 5D, $2^{\text {nd }}$ row), most of the golgin 97 exhibited a similar pattern to what was found in WT cells; with a small portion also appearing as part of small, punctate structures, perhaps as parts of the internal membrane organelles. In $N p c 1^{\text {nmf }}$ cells (Fig. 5D; $3^{\text {rd }}$ row), golgin 97 became dispersed, and scattered within the space around the nucleus. This distribution pattern is clearly distinct from that observed in WT cells and in $A 1^{-/-}$cells. Importantly, in $N p c 1^{n m f}: A 1^{-/}$cells (Fig. 5D; $4^{\text {th }}$ row), the abnormal golgin 97 localization pattern in $N p c 1^{n m f}$ cells was largely corrected. For clarity, enlarged (6-fold) versions of the merged images are provided

342 (Fig. 5D). We next performed double immunofluorescence experiments and monitored the 343 degree of apparent colocalization between syntaxin 6 and golgin 97 in these four cell types (Fig. $3445 \mathrm{D}, \mathrm{E})$. The results show that in WT and $A 1^{-/}$cells, the apparent colocalization between 345 syntaxin 6 and golgin 97 was relatively low (between $21 \%$ to $32 \%$ ). Mutation in NPC1 caused 346 the colocalization index to increase to $51 \%$; while $A 1$ deletion $\left(A 1^{-l_{-}}\right)$in the mutant $N p c 1^{\text {nmf }}$ cells 347 reduced the \% colocalization index back to $24 \%$, a value comparable to those observed in WT 348 and $A 1^{\%-}$ cells. Together, these results shown in Fig. 5A-E suggest that mutation of NPC1 349 causes a certain portion of the TGN membrane to become deficient in cholesterol; this 350 deficiency causes both syntaxin 6 and golgin 97 to become mislocalized from the rest of the 351 TGN. Importantly, ACAT1 blockage in mutant NPC1 cells largely corrects the abnormal 352 localization patterns of both syntaxin 6 and golgin 97. 
354 Effects of $A 1^{-/}$on the levels of cation-dependent manose-6-phosphate receptor (CD-

355 M6PR), and cathepsin D protein contents in mutant Npc ${ }^{\text {nmf }}$ MEFs. Syntaxin 6 is involved in

356 the anterograde vesicular trafficking of M6PRs/lysosomal hydrolase complexes (57). The cation-

357 dependent (CD) and cation-independent (CI) mannose-6-phosphate receptors (CD-M6PR and

358 Cl-M6PR) deliver newly synthesized lysosomal enzymes, which carry the mannose-6-

359 phosphate signal, from the TGN to the late endosomes. The M6PRs then recycle back to the

360 TGN for re-utilization, as reviewed in (58). Previously, Kobayashi et al. (59) showed that in

361 mutant NPC cells, the CD-M6PR localization pattern was altered, from mainly residing at the

362 TGN to mostlyly residing in the cholesterol-laden late endosomes. Ganley and Pfeffer (60)

363 showed that in mutant NPC cells, cholesterol accumulation caused CD-M6PR to be missorted

364 and rapidly degraded in late endo/lysosomes. Since we found that in mutant $N p c 1^{n m f}$ cells, $A 1^{-/-}$

365 rescued syntaxin 6 from mislocalization (Fig. 5A,B), we suspected that $A 1^{-/}$may also affect the

366 M6PR protein expression in mutant $N p c 1^{n m f}$ cells. To test this possibility, we performed Western

367 blot analyses to examine the levels of CD-M6PR protein in parallel cultures of MEFS of the four

368 genotypes. The results (Fig. 6A) show that when compared to WT cells, Npc1 ${ }^{n m f}$ cells express

369 CD-M6PR at levels less than $20 \%$ of values found in WT cells. In contrast, the Npc1 ${ }^{n m f}: A 1^{-/-}$cells

370 expressed CD-M6PR at levels more than 2-fold that of WT cells. This result suggests that

371 deleting $A 1$ was indeed more than sufficient to correct the low level of expression of the CD-

372 M6PR protein observed in $N p c 1^{n m f}$ cells. Interestingly, we also found that $A 1^{-/}$cells expressed

373 CD-M6PR level at $50 \%$ of values found in WT cells. At present, the significance of this finding is

374 unclear at present.

375

376 Cathepsin D is one of the major lysosomal enzymes that require M6PRs for processing at the

377 TGN. From the TGN, the cathepsin D/M6PR complexes move to LE/LYS for maturation by

378 proteolysis. Cathepsin D exists in various forms, including the precursor, intermediate, and

379 proteolytically cleaved mature heavy chain and light chain. These forms exhibit different

380 molecular weights on SDS-PAGE (61). Since we found that the expression level of CD-M6PR is

381 very low in mutant $N p c 1^{n m f}$ cells and $A 1^{-/}$corrected this deficiency (Fig. 6A), we postulated that

382 mutant $N p c 1^{n m f}$ MEFs may express lower level of cathepsin D protein (the mature heavy chain),

383 and that $A 1^{-/}$in mutant $N p c 1^{n m f}$ MEFs may correct this abnormality. To test this possibility, we

384 performed Western blot analysis with a highly specific, monoclonal antibody against the

385 cathepsin D mature form heavy chain. The results (Fig. 6 B) show that in both WT cells and $A 1^{1^{-/}}$

386 MEF cells, this antibody recognized the mature form of cathepsin $D$ heavy chain, which has an

387 apparent size of $30-32 \mathrm{kDa}$. Furthermore, WT and $A 1^{-/-}$cells expressed the mature form at 
comparable levels. In contrast, the mutant $N p c 1^{n m f}$ cells expressed cathepsin D at a level $64 \%$ less than that of WT cells and $A 1^{-/-}$cells. In addition, the size of the mature form of cathepsin D present in the NPC $1^{n m f}$ cells is slightly smaller (by 2-3 kDa) than that found in WT and $A 1^{-/-}$cells, suggesting that within the LE/LYS of $N p c 1^{n m f}$ cells, abnormal proteolytic cleavage of cathepsin D might occur. The $N p c 1^{n m f}: A 1^{-/-}$cells expressed cathepsin D with the same size as found in WT cells and $A 1^{-/-}$cells, with protein levels higher than those found in WT and $A 1^{-/-}$cells by $40 \%$.

394 Together, these results show that in $N p c 1^{n m f}$ cells, $A 1^{-/-}$reversed the diminished levels of CD-

395 M6PR and cathepsin D protein expression, consistent with both of these proteins being

396 downstream targets of syntaxin 6 mediated vesicular trafficking. We were curious as to whether

397 the diminished cathepsin D protein content observed in $N p c^{n m f}$ cells may affect their ability to

398 degrade proteins. To address this issue, we monitored the degradation of long-lived proteins by

399 using the procedure described by Auteri et al. (62). The result (Fig. 6C) shows that, instead, the

400 proteolysis of long-lived proteins in WT, $A 1^{-/-}, N p c 1^{n m f}$, and $N p c 1^{\mathrm{nmf}}: A 1^{-/-}$MEF cells was

401 comparable. This finding is consistent with the work of Pacheco et al. (63), who showed that

402 normal and NPC1-deficient human fibroblast (Hf) cells, the degradation of long-lived proteins

403 was comparable.

Effects of ACAT1 inhibition on ABCA1 and NPC1 protein levels in MEFs, in mouse cerebellum, and in human fibroblasts (Hfs). The results described above show that in

$407 N p c 1^{n m f}$ cells, the cathepsin D protein content is significantly decreased, and that the decrease 408 can be corrected by $A 1^{-/}$. To substantiate this finding, we sought to identify the relevant 409 downstream targets of cathepsin D mediated signaling and decided to focus on the ATP-binding 410 cassette transporter A1 (ABCA1). ABCA1 functions as a key cellular cholesterol efflux protein 411 [reviewed in (64)]. It is transcriptionally regulated by liver X receptors (LXRs) (65), (66) and post412 translationally regulated by various degradation mechanisms (67). In mutant Npc1 Hfs, Choi et 413 al. showed that the levels of both ACAT1 mRNA and protein are down regulated (68). In 414 addition, in macrophages and other cells, Haidar et al. showed that the ABCA1 protein content 415 is up-regulated by cathepsin D through a post-translational mechanism yet to be defined (69). In 416 various mammalian cell lines examined, blocking ACAT1 either by genetic inactivation or by 417 using a small molecule ACAT inhibitor increased the ABCA1 protein content; with the degree of 418 the ACAT inhibition affecting ABCA1 levels in a cell type dependent manner (70). On the other 419 hand, whether ACAT1 inhibition can increase ABCA1 in mutant NPC cells had not been 420 reported previously. Since we found that mutant $N p c 1^{n m f}$ MEF cells expressed the mature form 421 of cathepsin D at a level significantly lower than that in WT cells (Fig. 6B), we postulated that 
422 this abnormality may cause mutant $N p c 1^{n m f}$ MEF cells to express the ABCA1 protein at a lower

423 level, and that $A 1^{-1-}$ may be able to correct this deficiency. To test this possibility, we performed

424 Western blot analyses in parallel cultures of WT, $A 1^{-/}, N p c 1^{n m f}$, and $N p c 1^{n m f}: A 1^{-/}$MEFs. The

425 results show that the ABCA1 protein content in mutant Npc1 cells was lower than in WT cells or

426 in $A 1^{-/}$cells, and that $A 1^{-/}$in mutant $N p c 1^{n m f}$ cells restored $A B C A 1$ protein content to similar

427 level found in the WT cells (Fig. 7A). We prepared MEFs from WT and mutant mice that

428 completely lacking NPC1 (the $N p c 1^{\text {nih }}$ mouse model with a BALB/c genetic background), and

429 found that the ABCA1 protein content in the $N p c 1^{\text {nih }}$ MEFs was also significantly lower than that

430 in the control WT MEF cells (Fig. 7A; top row; comparing the last 2 lanes on the right). These

431 results show that in MEFs, $A 1^{-/-}$restore the diminished protein content of $A B C A 1$ in $N p c 1^{\text {nmf }}$

432 cells. We also performed Western blot analyses to monitor the NPC1 protein content (Fig. 7A;

433 second row) that in mutant $N p c 1^{m n f}$ cells, NPC1 protein content was significantly lower than

434 that in WT or $A 1^{-/}$cells, confirming our previous report (46). $A 1^{-/}$in mutant Npc1 cells had a

435 tendency to increase mutant NPC1 protein content, but the effect did not reach statistical

436 significance (Fig. 7A). To serve as a control, additional results show that unlike WT MEFs,

437 NPC1 protein was completely absent from Npc1 ${ }^{\text {nih }}$ MEFs (Fig. 7A). We next determined the 438 level of ABCA1 mRNA in parallel cultures of WT, $A 1^{-/}, N p c 1^{n m f}$, and $N p c 1^{n m f}: A 1^{-/}$MEFs by RT-

439 PCR. The results (Fig. 7B) show that, similar to the finding by Choi et al. in Hfs (68), the ABCA1 440 mRNA level in $N p c 1^{n m f}$ cells is lower than that in WT cells. Furthermore, in both WT and $N p c 1^{n m f}$ 441 cells, $A 1^{-/}$caused increase in the level of ABCA1 mRNA. This result supports the interpretation 442 that in mutant NPC1 cells, $A 1^{-/-}$restored the level of ABCA1 protein, at least in part, by restoring 443 cathepsin D function in late endo/lysosomes.

445 To test the in vivo significance of these findings, we next performed similar Western blot

446 analyses of homogenates prepared from P80 mouse cerebellum. The results show that in

447 mutant Npc1 cerebellum, $A 1^{-/}$significantly increased ABCA1 protein abundance (Fig. 7C; left

448 panel at the bottom; comparing the $3^{\text {rd }}$ bar versus the $4^{\text {th }}$ bar). $A 1^{-/ \text {had }}$ a tendency to also

449 increase the mutant NPC1 protein content, but the effect did not reach statistical significance

450 (Fig. 7C; right panel at the bottom; comparing the $3^{\text {rd }}$ bar versus the $4^{\text {th }}$ bar). These results

451 demonstrate that the restorative effect of $A 1^{-/}$on the low level of ABCA1 protein found in mutant

452 NPC1 MEF can be replicated in P80 mouse cerebellum. 
455 To determine if the beneficial effect of $A 1^{-/}$on increasing the ABCA1 protein level in MEFs with

456 an NPC mutation can also be observed in Hfs isolated from patients, we treated Hfs isolated

457 from one normal individual, four NPC1 patients, and one Niemann-pick disease type A (NPA)

458 patient (as indicated in Fig. 7D) with the small molecule ACAT1 specific inhibitor K604 at $0.5 \mu \mathrm{M}$

459 for $24 \mathrm{~h}$. At this concentration, K604 is expected to inhibit the ACAT1 enzyme activity in intact

460 cells by approximately 70-80\% (71). The results (Fig. 7D, E) show that K604 modestly

461 increased the ABCA1 protein in normal Hf, and in one of four different mutant NPC1 Hfs (line

462 GM03123). In the second Hf with mutant NPC1 (GM18453), in one Hf with mutant NPA

463 (GM00112), and in one Hf with mutant NPC2 (GM17910), K604 tended to increase the ABCA1

464 protein, but the difference did not reach statistical significance. These results show that the

465 enhancing effects of ACAT1 inhibition on ABCA1 protein levels observed in mutant Npc1 $1^{\text {nmf }}$

466 MEFs can be demonstrated in at least some Hfs with NPC1 mutations. 


\section{Discussion}

We genetically inhibited ACAT1 in a mouse model of NPC1 disease $\left(N p c 1^{\text {nmf }}\right)$ and show that $A 1^{-/-}$ delays the onset of weight loss and declining sensorimotor skill, ameliorates certain systemic and neuropathological NPC disease hallmarks, and prolongs the life span by $34 \%$. This "rescue" of $N p c 1^{n m f}$ mice by $A 1^{-/-}$is rather surprising, and while similar attempts to extend lifespan have been made by genetic crossing of mutant NPC1 mice with mice lacking genes that encode one of the following proteins: LDL receptor (72), ApoE (73), SRBI (74), GM2 synthetase (75), GM3 synthetase (76), glucocerebrosidase 2 (77), Tau (78), and RIPK1 (a key protein that mediates necroptosis) (79), to our knowledge the current study is the first to demonstrate that knockout of a single gene can extend the life span of a mutant Npc1 mouse model by more than $30 \%$.

To provide a mechanistic basis for the beneficial effects of ACAT1 inhibition at the cellular level, we studied MEFs isolated from WT, $A 1^{-/-}, N p c 1^{n m f}$, and $N p c 1^{n m f}: A 1^{-/-}$mice, and show that in mutant NPC1 MEFs, ACAT1 inhibition alters membrane cholesterol distribution, and restores the mislocalization of syntaxin 6 , a cholesterol-binding t-SNARE that normally localizes to the TGN and mediates the anterograde vesicular trafficking of the M6PRs/lysosomal hydrolase complexes. In addition to syntaxin 6, we show in mutant NPC1 cells that golgin 97, a different TGN marker, also mis-localized, and $A 1^{-/-}$can restore normal golgin 97 localization at the TGN . These results suggest that mutation of NPC1 causes a certain portion of the TGN membrane to become deficient in cholesterol and that ACAT1 inhibition in mutant NPC1 cells corrects the abnormal localization patterns of both syntaxin 6 and golgin 97 by replenishing cholesterol in the TGN membrane. We also show that mutant NPC cells express diminished level of protein

490 further downstream, such as CD-M6PR and cathepsin D (one of the key lysosomal hydrolases), 491 and that $A 1^{-/-}$restores the levels of these proteins as well. These results imply that $A 1^{-/-}$restores 492 the localization and functionality of syntaxin 6 in mutant NPC1 cells. To link the changes in 493 cathepsin D with its downstream target(s), we also show that $A 1^{-/-}$restores the diminished 494 ABCA1 protein content observed in mutant NPC1 cells and in mutant NPC1 cerebellum. Based 495 on these results, we propose a model to explain the actions of ACAT1 blockage: In mutant NPC 496 cells, the inability of NPC to export cholesterol from the LE/LYS causes several membrane 497 organelles downstream of NPC mediated cholesterol trafficking pathway to become deficient in 498 cholesterol which leads to malfunctions in these organelles. ACAT1 resides at a certain 499 subdomain (designated as the A1 domain) of the ER. Despite the mutation in NPC, certain 500 cholesterol continues to arrive at the A1 domain, in an NPC independent manner, to be 
esterified by A1. ACAT1 inhibition causes the cholesterol pool associated with the A1 domain to translocate to other subcellular membrane compartments. The diversion of the cholesterol storage pool fulfills the needs of these membrane compartments for cholesterol and helps them regain their proper function. In the current work, we demonstrate that the TGN is one of the recipient organelles that benefits from ACAT1 inhibition. Results presented in Fig. 4A-D provide indirect evidence suggesting that in mutant NPC cells, $A 1^{-/-}$may also increase the cholesterol content in other membrane compartments including the PM and perhaps the limiting membrane

508 of the LE/LYS. Further investigations will be required to test these possibilities. It is possible that 509 cholesterol translocation processes exist between the A1 microdomain and the microdomains present in other subcellular organelles, and that inhibition of A1 facilitates the cholesterol transfer from the A1 domain to these other membrane organelles. Multiple contact sites have

512 been shown to exist between the ER membranes and other membrane organelles including PM, 513 Golgi, mitochondria, and endosomes, as reviewed in (80), (81), (82), (83). The sterol transfer process between the A1 microdomain and other membrane microdomain(s) may occur through these membrane contact sites. Future work will be needed to reveal the molecular nature of the hypothetical cholesterol translocation pathways between the A1 domain and other membrane organelles.

The current study identifies ACAT1 as a new potential target for treating patients with NPC disease. It is important to evaluate the pros and cons of using small molecule ACAT inhibitors to treat NPC disease and other related diseases. At the cell culture level, studies have shown

522 that when the cholesterol efflux process is absent (i.e., by placing cells in growth medium

523 without any cholesterol acceptors present, or by studying cells that lack ABCA1), ACAT

524 inhibition produced cytotoxicity (84), (33). When the cellular cholesterol efflux process is active

525 (i.e., by including cholesterol acceptors such as apoA1 or serum lipoproteins in the growth

526 medium), however inhibiting A1 does not cause detectable cellular toxicity (85), (86), (87). It is

527 possible that the buildup of free (unesterified) cholesterol in cell membranes may need to reach

528 certain threshold level before it becomes toxic to cells. At the in vivo level, mouse gene $\mathrm{KO}(\mathrm{KO})$

529 studies show that Acat1 KO $\left(A 1^{-/}\right)$mice exhibit dry skin, dry eye syndrome (88), (89), and

530 leukocytosis (90), but their adrenal functions are normal (47) and their ability to learn and

531 memorize are also normal (91). At the human level, at least two adult humans with presumed

532 homozygous knockout mutations for SOAT1 or SOAT2 have been identified, and neither has

533 obviously noticeable issues (92). Interestingly, recent studies have shown that, in mouse

534 models, total $A 1^{-/}$reduces pathologies associated with Alzheimer's disease (91). Myeloid $A 1^{-/}$ 
535 suppresses atherosclerosis development and progression (93), (94), and suppresses diet

536 induced obesity (95). Additional studies show that inhibiting A1 suppresses the development

537 and progression of pancreatic cancer (96), suppresses the development of hepatocellular

538 carcinoma (97), and potentiates the antitumor activities of cytotoxic T cells (98). Collectively,

539 these studies suggest that if employed properly, ACAT1 may be a promising target for treating

540 multiple human diseases. ACAT inhibitors of various structural types are available. In many

541 cases they were developed with the original intention to treat cardiovascular diseases, and

542 several of these inhibitors have passed a phase-I safety test for anti-atherosclerosis treatment.

543 For safety reasons, it will be important to begin testing the ACAT inhibitors in NPC patients (and

544 patients with other diseases) who do not also have partial deficiencies in other genes involved in

545 the cellular cholesterol efflux process.

\section{Materials and Methods}

\section{Materials}

\section{Chemical reagents:}

553 Fetal bovine serum was purchased from Sigma. Iron-supplemented calf serum was purchased

554 from Atlanta Biologicals. OptiPrep was obtained from Axis-Shield. ${ }^{3} \mathrm{H}$-labeled acetate and ${ }^{3} \mathrm{H}$ -

555 labeled oleate were acquired from PerkinElmer. All chemicals (analytical grade) were purchased

556 from Sigma-Aldrich or Fisher. Low-density lipoproteins (LDL) from fresh human blood and delipidated serum from fetal bovine serum stock were prepared as previously described (99).

\section{Histological reagents:}

$\begin{array}{llllc}\begin{array}{l}\text { Reagent type } \\ \text { or resource }\end{array} & \text { Designation } & \begin{array}{l}\text { Source or } \\ \text { reference }\end{array} & \text { Identifiers } & \begin{array}{c}\text { Additional } \\ \text { information }\end{array} \\ 2^{\circ} \text { Antibody } & \text { Alexa fluor } 568 & \text { Molecular Probe } & & 1: 500 \\ 2^{\circ} \text { Antibody } & \text { Alexa fluor } 488 & \text { Molecular Probe } & & 1: 500 \\ \text { Antibody } & \text { ABCA1 } & \text { Novus } & \text { NB-400-105 } & 1: 500 \\ \text { Antibody } & \text { B-Tubulin } & \text { GenScript } & \text { A01717 } & 0.16 \mu \mathrm{g} / \mathrm{ml} \\ \text { Antibody } & \text { Calnexin } & \text { GenScript } & \text { A01234 } & 1 \mu \mathrm{g} / \mathrm{ml} \\ \text { Antibody } & \text { Cathepsin D } & \text { Santa Cruz } & \text { SC-6486 } & 1: 200\end{array}$




\begin{tabular}{|c|c|c|c|c|c|}
\hline $\begin{array}{l}575 \\
576\end{array}$ & Antibody & Caviolin 1 & Santa Cruz & SC-894 & $1: 500$ \\
\hline $\begin{array}{l}577 \\
578\end{array}$ & Antibody & CD-M6PR & Novus & NBP-1-20167 & $1: 500$ \\
\hline $\begin{array}{l}579 \\
580\end{array}$ & Antibody & Cyto C Oxidase I & Santa Cruz & SC-58347 & $1: 200$ \\
\hline $\begin{array}{l}581 \\
582\end{array}$ & Antibody & Golgin 97 & Invitrogen & A-21270 & $1: 500$ \\
\hline $\begin{array}{l}583 \\
584\end{array}$ & Antibody & LAMP1 & Cell Signaling & D401S & $1: 1000$ \\
\hline $\begin{array}{l}585 \\
586\end{array}$ & Antibody & NCP1 & William S Garv & & \\
\hline $\begin{array}{l}587 \\
588\end{array}$ & Antibody & Syntaxin 6 & Andrew A Ped & & \\
\hline $\begin{array}{l}589 \\
590\end{array}$ & Antibody & Vinculin & Millipore & $05-386$ & $1: 2500$ \\
\hline $\begin{array}{l}591 \\
592 \\
593\end{array}$ & $\begin{array}{l}\text { Fluorescent } \\
\text { Probe }\end{array}$ & DAPI & CalBiochem & 26898 & $0.2 \mu \mathrm{g} / \mathrm{ml}$ \\
\hline $\begin{array}{l}594 \\
595 \\
596 \\
597\end{array}$ & $\begin{array}{l}\text { Fluorescent } \\
\text { Probe }\end{array}$ & Filipin & Sigma & F-9765 & $0.05 \mathrm{mg} / \mathrm{ml}$ \\
\hline $\begin{array}{l}598 \\
599\end{array}$ & \multicolumn{5}{|c|}{ Primers used for ACAT1 mouse genotyping: } \\
\hline $\begin{array}{l}600 \\
601 \\
602 \\
603\end{array}$ & WT: & $\begin{array}{l}\text { Forward primer: } \\
\text { Reverse primer: } \\
\text { Amplicon size: }\end{array}$ & \multicolumn{3}{|c|}{$\begin{array}{l}\text { 5'-GGTGTTCACATGGTGCACAGATAC-3' } \\
\text { 5'-GACTTTTCAATGAGGTTGGTCACA-3' } \\
445 \mathrm{bp}\end{array}$} \\
\hline $\begin{array}{l}604 \\
605 \\
606 \\
607 \\
608\end{array}$ & Mutant: & $\begin{array}{l}\text { Forward primer: } \\
\text { Reverse primer: } \\
\text { Amplicon size: }\end{array}$ & \multicolumn{3}{|c|}{$\begin{array}{l}\text { 5'-GGTGTTCACATGGTGCACAGATAC-3' } \\
\text { 5'-AGGATCTCCTGTCAT CTC ACC TTG CTC CTG } \\
1052 \text { bp }\end{array}$} \\
\hline $\begin{array}{l}609 \\
610\end{array}$ & \multicolumn{5}{|c|}{ Primer sequences used for real time PCR (RT-PCR) analysis: } \\
\hline 611 & \multirow[t]{2}{*}{ Gene } & \multirow{2}{*}{\multicolumn{2}{|c|}{ Sense/Antisense }} & \multirow{2}{*}{\multicolumn{2}{|c|}{ Amplicon size (bp) }} \\
\hline 612 & & & & & \\
\hline 613 & \multirow[t]{3}{*}{ Calbindin } & \multicolumn{3}{|c|}{ 5'-GAGCTATCACCGGAAATGAAA-3' } & 152 \\
\hline 614 & & \multicolumn{3}{|c|}{ 5'-AATTCCTCGCAGGACTTCAG-3' } & \\
\hline 615 & & & & & \\
\hline 616 & \multirow[t]{2}{*}{$\mathrm{ABCA} 1$} & \multicolumn{3}{|c|}{ 5'-GGTTTGGAGATGGTTATACAATAGTTGT-3' } & 96 \\
\hline 617 & & \multicolumn{3}{|c|}{ 5'-TTCCCGGAAACGCAAGTC-3' } & \\
\hline 618 & & & & & \\
\hline 619 & \multirow[t]{2}{*}{ GAPDH } & \multicolumn{3}{|c|}{ 5"-ATGGTGAAGGTCGGTGTG-3' } & 186 \\
\hline 620 & & \multicolumn{3}{|c|}{ 5'-CATTCTCGGCCTTGACTG-3' } & \\
\hline
\end{tabular}




\section{Methods}

Animal maintenance: Mice were fed ad libitum with standard chow diet, maintained in a pathogen-free environment in single-ventilated cages, and kept on a $12 \mathrm{~h}$ light/dark schedule, using Dartmouth Animal Research Center Institutional Animal Care and Use Committeeapproved protocol number 00002020. Animals were checked daily for their entire lifespan. When $N p c 1^{n m f}$ mice began to have trouble reaching food, wet food pellets were placed on the bottom of their cage for the remainder of their life. Death was marked as the point where the mice could no longer ingest food or water.

Mouse breeding: The heterozygous mutant NPC1 mouse in C57BL/6J background

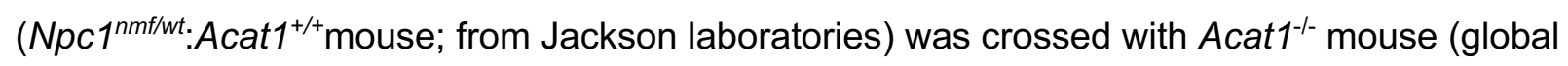
ACAT1 KO mouse) [(47); received from Dr. Sergio Fazio in C57BL/6J background], to produce $N p c 1^{\text {nmf } / w t}$ :Acat $1^{-1-}$ mice and $N p c 1^{\text {nmfwt }}$ Acat $1^{1++}$ mice. After two rounds of breeding, the resultant $N p c 1^{n m f / w t}:$ Acat $1^{-/-}$mice were set up as breeding pairs to generate the $N p c 1^{n m f / n m f}:$ Acat $1^{-/}$mice (Designated as $N p c 1^{n m f}: A 1^{-/}$mice) and $N p c 1^{w t w t}$ :Acat $1^{-/}$mice (Designated as $A 1^{-/}$mice). The $N p c 1^{n m f / w t}: A 1^{1 /+}$ mice were set up as breeding pairs to generate $N p c 1^{n m f / n m f}: A 1^{+/+}$mice (Designated as $N p c 1^{n m f}$ mice) and $N p c 1^{w t w t}: A 1^{+/+}$mice (Designated as WT mice).

NPC $1^{\text {nmf }}$ mouse genotyping: The protocol described by (46) was followed with minor modification: $10 \mu$ of reaction buffer containing $10 \mathrm{ng}$ of mouse-tail genomic DNA, 1x TaqMan genotyping master mix, and $1 \times$ SNP Custom TaqMan SNP assay mixture. The PCR reaction was carried out by amplifying at $95^{\circ} \mathrm{C}$ for $5 \mathrm{~min}$, followed by 45 cycles of: $92^{\circ} \mathrm{C}$ for $15 \mathrm{~s}$ and $60^{\circ} \mathrm{C}$ for $1 \mathrm{~min}$.

ACAT1 mouse genotyping: PCR conditions were: $94^{\circ} \mathrm{C}$ for $1.5 \mathrm{~min}$, followed by 35 rounds of: $94^{\circ} \mathrm{C}$ for $30 \mathrm{~s}, 62^{\circ} \mathrm{C}$ for $60 \mathrm{~s}, 72^{\circ} \mathrm{C}$ for $60 \mathrm{~s}$. Lastly, $72^{\circ} \mathrm{C}$ for $2 \mathrm{~min}$. The primers used are described above in the Materials.

\section{Mouse motor skills: Mouse motor skills were assessed by RotaRod test using a} commercially available instrument (purchased from Med Associates Inc, Fairfax, VT) in a manner similar to what was previously reported (100), with slight modifications. Briefly, after a brief initial training period, mouse motor skills were monitored from six weeks postnatal age until failure. Each week mice were given three consecutive trials on a constant speed rotarod at 24 rotations per min for up to $90 \mathrm{~s}$ for each of the three trials. WT and $A 1^{-/}$mice passed all trials 
656 running for at least $10 \mathrm{~s}$ on any of the three consecutive trials during every week assessed. Age

657 of rotarod test failure in $N p c 1^{n m f}$ and $N p c 1^{n m f}: A 1^{-/}$mice was measured as the age at which mice

658 failed to run on the rotarod for at least $10 \mathrm{~s}$ during at least one of the three consecutive trials.

659 Rotarod trial failure included falling off the rod before $10 \mathrm{~s}$ or freezing and clasping to the rotarod 660 and not running or moving.

Histological analyses: Hematoxylin and Eosin staining of mouse liver, spleen and lung tissues, and Purkinje neurons in cerebellum at postnatal day 80 were performed by the Histology Service at the Jackson Laboratory, using standard protocols in a Leica Autostainer XL automated processor.

Cell culture: MEFs were isolated according the procedure described (101). MEF were grown as monolayers at $37^{\circ} \mathrm{C}$ with $5 \% \mathrm{CO}_{2}$ in DMEM supplemented with $10 \%$ serum and MEM nonessential amino acids (Gibco), or with $5 \%$ delipidated fetal bovine serum and $35 \mu \mathrm{M}$ oleic acid, and with penicillin/streptomycin. Each experiment was performed with cells grown in triplicate 671 dishes.

Degradation of long-lived proteins in MEFs: The procedure described in (62), (63) was adopted with minor modification. MEFs were seeded on 12-well plates at a density of $0.012 \times 10^{6}$ cells in triplicate. Media were replaced the night before the experiment. Cells were rinsed with 2 $\mathrm{ml}$ of MEM and labeled with $1 \mathrm{ml}$ of $2 \mu \mathrm{Ci} / \mathrm{ml}$ of ${ }^{3} \mathrm{H}$ leucine in MEM+10\% serum. At time zero, cells were washed twice with HBSS, then chased by $1 \mathrm{ml} \mathrm{MEM+2.8} \mathrm{mM} \mathrm{leucine} \mathrm{without} \mathrm{serum.}$ At each time point indicated, media were transferred to a microcentrifuge tube, trichloroacetic acid added to a final concentration of $20 \%$ and BSA to a final concentration of $3 \mathrm{mg} / \mathrm{ml}$. Samples were incubated at $4^{\circ} \mathrm{C}$ for $1 \mathrm{~h}$, centrifuged at $15,000 \mathrm{~g}$ at $4^{\circ} \mathrm{C}$ for $5 \mathrm{~min}$, supernatants and pellets were collected. Ecoscint $\mathrm{H}$ was added for scintillation counting. Cells were washed with PBS and incubated in $0.1 \mathrm{M} \mathrm{NaOH}$ in $0.1 \%$ deoxycholate for $1 \mathrm{~h} .40 \mu \mathrm{l}$ in duplicates were

683 aliquoted for protein determination.

\section{Western blot analyses:}

686 From either freshly isolated mouse cerebellum tissues or tissue culture cells: it was prepared in 687 either 10\% SDS (for syntaxin 6, CD-M6PR, NPC1, or cathepsin D), or RIPA buffer (for ABCA1), 688 plus protease inhibitor (Sigma), and homogenized in a stainless-bed Bullet Blender twice for 3 $689 \min$ each at $4^{\circ} \mathrm{C}$. Homogenized lysates were run on a $6 \%$ gel (for ABCA1), $10 \%$ gel (NPC1, 690 LAMP1) or 12\% gel (for Syntaxin 6, CD-M6PR, Cathepsin D, Caveolin 1, and Cytochrome C 
691 Oxidase), and transferred to PVDF membrane in Towbin buffer. Signal intensities were

692 normalized to vinculin (117-kDa) or B tubulin (50-kDa) expression by NIH Imaging software.

694 RNA isolation and real-time PCR (RT-PCR) experiments: Total RNA was isolated from

695 TRIzol reagent (Invitrogen) following the manufacturer's instruction. The RNA was dissolved in

696 sterile water treated with DNasel (Ambion). $1 \mu \mathrm{g}$ of RNA was used to synthesize cDNA,

697 according to the instructions in the BioRad iScript cDNA Synthesis Kit. Real-time PCR was

698 carried out using the iTaq Universal SYBR Green Supermix (from Bio-Rad) with the Applied

699 Biosystems Step One RT-PCR system. Relative quantification was determined by using the

700 delta CT method. The primer sequences used are listed above in the Materials. The PCR

701 reaction conditions were as described previously (91).

Subcellular fractionation: Procedures were carried out as described previously (22). Cells

704 grown in one 150-mm dish to near confluence were washed twice with phosphate-buffered

705 saline, once with homogenization buffer $(\mathrm{HB}, 250 \mathrm{mM}$ sucrose, $20 \mathrm{mM}$ Tris- $\mathrm{HCl}, \mathrm{pH} 7.4,1 \mathrm{mM}$

706 EDTA), harvested to $1 \mathrm{ml} \mathrm{HB}$ with protease inhibitors, and homogenized by using a stainless-

707 steel homogenizer with 40 strokes. The post-nuclear supernatants were placed onto the top of

708 an $11 \mathrm{ml} 5-25 \%$ OptiPrep discontinuous gradient in HB. The gradient was centrifuged at

$709200,000 \times g(40,000$ rpm) for $3 \mathrm{~h}$ in a Beckman SW41 rotor; 15 fractions (800 $\mu$ l each) were

710 collected from the top.

712 Lipid syntheses in intact cells: The analysis of cholesterol biosynthesis in intact cells was

713 carried out as previously described (102), exposing cells to ${ }^{3} \mathrm{H}$-labeled acetate for $1 \mathrm{~h}$ followed

714 by lipid extraction. The measurement of cholesterol esterification in intact cells was performed

715 by exposing cells to ${ }^{3} \mathrm{H}$-labeled oleate/BSA for $1 \mathrm{~h}$ followed by lipid extraction and analysis, as

716 previously described (103).

718 Fluorescence microscopy: MEF cells were cultured on poly-D-Lysine (70-150kDa) glass

719 coverslips (MatTek) in 12-well plates for $24 \mathrm{~h}$, and fixed in 4\% paraformaldehyde (EMS) at RT

720 for $10 \mathrm{~min}$. After washing with PBS, the cells were permeabilized with $0.3 \%$ Triton X-100 for 20

721 min. Cells were then washed with PBS prior to blocking with $5 \%$ goat serum in PBS for $1 \mathrm{~h}$ at

722 RT, followed by staining with primary antibodies for at least $1 \mathrm{~h}$ at RT. Cells were washed with

723 PBS before and after incubation with Alexa Fluor 568 or Alexa Fluor 488 as the secondary

724 antibodies at 1:500 dilution for $1 \mathrm{~h}$ at RT, DNA was counter stained with DAPI $(0.2 \mu \mathrm{g} / \mathrm{ml})$ at RT

725 for $10 \mathrm{~min}$ to visualize the nucleus. 
726 To identify cellular cholesterol, cells were fixed in 4\% paraformaldehyde (without the use of

727 detergent), after several washes, cells were pre-incubated with $1.5 \mathrm{mg} / \mathrm{ml}$ glycine in PBS for 10

$728 \mathrm{~min}$ at RT, then incubated with Filipin $(50 \mu \mathrm{g} / \mathrm{ml})$ at RT for $1 \mathrm{~h}$ as previously described (104).

Images were acquired by using the Andor W1 Spinning Disk Confocal system (Nikon Eclipse Ti inverted microscope, and Andor Zyla camera), with a 60x oil-immersion lens, using three laser lines (403-nm laser for DAPI, 488-nm and 561-nm filters for FITC and Texas Red respectively). Z-stacked fluorescent images were taken by 11 optical slices at $0.2 \mu \mathrm{m}$ intervals to enhance the spatial signal allocation. Images were visualized by using Fiji-Image J Software, and processed using Nikon Elements to create the "Maximum Intensity Projection", and calculate the Pearson's correlation coefficient. The Reflex angle was determined according to Mitchel et al. (55), as the angle subtended by the edges of the positive fluorescence signals, using the center of the nucleus (based on the DAPI positive signal) as the vertex.

Statistical analysis: Statistical comparisons were made by using a two-tailed, unpaired $P$ value was less than 0.05 . ( $\left.p<0.0001^{* * * *}, p<0.001^{* * *}, p<0.01^{* *}, p<0.05^{*}\right)$. n.s. indicates the differences were not significant.

\section{Author contributions and Conflict of interest statement} performed research; R.A.M., A.P., and W.G. contributed new reagents/analytic tools; C.C.Y.C., M.A.R., R.A.M. and T.-Y.C. analyzed data; T.-Y.C., M.A.R., and C.C.Y.C., wrote the paper. All authors approved the final version of the manuscript.

The authors declare no conflict of interest.

\section{Acknowledgments}

753 We thank Drs. Ann Lavanway, Wen-Lih Lee, Safia Omer, Zdenek Svindrych and Lona Young

754 for advice in confocal microscopy usage, we thank Dr. Henry Higgs for providing the anti-golgin

75597 antibodies. We thank Yohei Shibuya and other members of the Chang lab for helpful

756 discussions during the course of this work. We also thank Dr. Gustav Lienhard for careful

757 reading of this manuscript.

758 This work was supported by NIH grant R01 AG063544 (to T.Y. Chang and C.C.Y. Chang). We

759 acknowledge the shared facilities of the pre-clinical imaging and microscopy resource at the 
Norris Cotton Cancer Center at Dartmouth with NCl Cancer Center Support Grant 5P30 CA023108-41, and a grant P20-GM113132 to support Institute for Biomolecular Targeting at Dartmouth. The content is solely the responsibility of the authors and does not necessarily represent the official views of the National Institutes of Health.

\section{REFERENCES}

1 Carstea, E.D., Morris, J.A., Coleman, K.G., Loftus, S.K., Zhang, D., Cummings, C., Gu, J., Rosenfeld, M.A., Pavan, W.J., Krizman, D.B. et al. (1997) Niemann-Pick C1 disease gene: homology to mediators of cholesterol homeostasis. Science, 277, 228-231.

2 Loftus, S.K., Morris, J.A., Carstea, E.D., Gu, J.Z., Cummings, C., Brown, A., Ellison, J., Ohno, K., Rosenfeld, M.A., Tagle, D.A. et al. (1997) Murine model of Niemann-Pick C disease: mutation in a cholesterol homeostasis gene. Science, 277, 232-235.

3 Naureckiene, S., Sleat, D.E., Lackland, H., Fensom, A., Vanier, M.T., Wattiaux, R., Jadot, M. and Lobel, P. (2000) Identification of HE1 as the second gene of Niemann-Pick C disease. Science, 290, 2298-2301.

4 Pentchev, P.G., Comly, M.E., Kruth, H.S., Tokoro, T., Butler, J., Sokol, J., Filling-Katz, M., Quirk, J.M., Marshall, D.C., Patel, S. et al. (1987) Group C Niemann-Pick disease: faulty regulation of low-density lipoprotein uptake and cholesterol storage in cultured fibroblasts. FASEB J, 1, 40-45.

$5 \quad$ Vanier, M.T. (1999) Lipid changes in Niemann-Pick disease type C brain: personal experience and review of the literature. Neurochem. Res., 24, 481-489.

6 Pineda, M., Walterfang, M. and Patterson, M.C. (2018) Miglustat in Niemann-Pick disease type C patients: a review. Orphanet J Rare Dis, 13, 140.

7 Ory, D.S., Ottinger, E.A., Farhat, N.Y., King, K.A., Jiang, X., Weissfeld, L., Berry-Kravis, E., Davidson, C.D., Bianconi, S., Keener, L.A. et al. (2017) Intrathecal 2-hydroxypropyl-betacyclodextrin decreases neurological disease progression in Niemann-Pick disease, type C1: a non-randomised, open-label, phase 1-2 trial. Lancet, 390, 1758-1768.

$8 \quad$ Vance, J.E. and Karten, B. (2014) Niemann-Pick C disease and mobilization of Iysosomal cholesterol by cyclodextrin. Journal of lipid research, 55, 1609-1621.

9 Brown, M.S. and Goldstein, J.L. (1986) A receptor-mediated pathway for cholesterol homeostasis. Science, 232, 34-47.

10 Ohgami, N., Ko, D.C., Thomas, M., Scott, M.P., Chang, C.C. and Chang, T.Y. (2004) Binding between the Niemann-Pick $\mathrm{C} 1$ protein and a photoactivatable cholesterol analog requires a functional sterol-sensing domain. Proc Natl Acad Sci U S A, 101, 12473-12478. 11 Infante, R.E., Abi-Mosleh, L., Radhakrishnan, A., Dale, J.D., Brown, M.S. and Goldstein, J.L. (2008) Purified NPC1 protein. I. Binding of cholesterol and oxysterols to a 1278-amino acid membrane protein. J Biol Chem, 283, 1052-1063.

12 Friedland, N., Liou, H.L., Lobel, P. and Stock, A.M. (2003) Structure of a cholesterolbinding protein deficient in Niemann-Pick type C2 disease. Proc Natl Acad Sci U S A, 100, 2512-2517.

13 Cheruku, S.R., Xu, Z., Dutia, R., Lobel, P. and Storch, J. (2006) Mechanism of cholesterol transfer from the Niemann-Pick type C2 protein to model membranes supports a role in lysosomal cholesterol transport. J. Biol. Chem., 281, 31594-31604.

14 Pfeffer, S.R. (2019) NPC intracellular cholesterol transporter 1 (NPC1)-mediated cholesterol export from lysosomes. J Biol Chem, 294, 1706-1709. 
15 Wojtanik, K.M. and Liscum, L. (2003) The transport of LDL-derived cholesterol to the plasma membrane is defective in NPC1 cells. J. Biol. Chem., 278, 14850-14856. 16 Das, A., Brown, M.S., Anderson, D.D., Goldstein, J.L. and Radhakrishnan, A. (2014) Three pools of plasma membrane cholesterol and their relation to cholesterol homeostasis. Elife, 3.

17 Underwood, K.W., Jacobs, N.L., Howley, A. and Liscum, L. (1998) Evidence for a cholesterol transport pathway from lysosomes to endoplasmic reticulum that is independent of the plasma membrane. J Biol Chem, 273, 4266-4274.

18 Du, X., Kumar, J., Ferguson, C., Schulz, T.A., Ong, Y.S., Hong, W., Prinz, W.A., Parton,

817 R.G., Brown, A.J. and Yang, H. (2011) A role for oxysterol-binding protein-related protein 5 in

818 endosomal cholesterol trafficking. The Journal of cell biology, 192, 121-135.

81919 Hoglinger, D., Burgoyne, T., Sanchez-Heras, E., Hartwig, P., Colaco, A., Newton, J.,

820 Futter, C.E., Spiegel, S., Platt, F.M. and Eden, E.R. (2019) NPC1 regulates ER contacts with

821 endocytic organelles to mediate cholesterol egress. Nat Commun, 10, 4276.

$822 \quad 20 \quad$ Zhao, K. and Ridgway, N.D. (2017) Oxysterol-Binding Protein-Related Protein 1L

823 Regulates Cholesterol Egress from the Endo-Lysosomal System. Cell Rep, 19, 1807-1818.

82421 Chu, B.B., Liao, Y.C., Qi, W., Xie, C., Du, X., Wang, J., Yang, H., Miao, H.H., Li, B.L.

825 and Song, B.L. (2015) Cholesterol transport through lysosome-peroxisome membrane contacts.

826 Cell, 161, 291-306.

$82722 \quad$ Urano, Y., Watanabe, H., Murphy, S.R., Shibuya, Y., Geng, Y., Peden, A.A., Chang, C.C. and Chang, T.Y. (2008) Transport of LDL-derived cholesterol from the NPC1 compartment to the ER involves the trans-Golgi network and the SNARE protein complex. Proc Natl Acad Sci U S A, 105, 16513-16518.

23 Reverter, M., Rentero, C., de Muga, S.V., Alvarez-Guaita, A., Mulay, V., Cairns, R., Wood, P., Monastyrskaya, K., Pol, A., Tebar, F. et al. (2011) Cholesterol transport from late endosomes to the Golgi regulates t-SNARE trafficking, assembly, and function. Mol Biol Cell, 22, 4108-4123.

24 Abdul-Hammed, M., Breiden, B., Schwarzmann, G. and Sandhoff, K. (2017) Lipids regulate the hydrolysis of membrane bound glucosylceramide by lysosomal betaglucocerebrosidase. J Lipid Res, 58, 563-577.

25 Reverter, M., Rentero, C., Garcia-Melero, A., Hoque, M., Vila de Muga, S., AlvarezGuaita, A., Conway, J.R., Wood, P., Cairns, R., Lykopoulou, L. et al. (2014) Cholesterol regulates Syntaxin 6 trafficking at trans-Golgi network endosomal boundaries. Cell Rep, 7, 883897.

26 Yu, W., Gong, J.S., Ko, M., Garver, W.S., Yanagisawa, K. and Michikawa, M. (2005) Altered cholesterol metabolism in Niemann-Pick type $\mathrm{C} 1$ mouse brains affects mitochondrial function. J Biol Chem, 280, 11731-11739.

27 Charman, M., Kennedy, B.E., Osborne, N. and Karten, B. (2010) MLN64 mediates egress of cholesterol from endosomes to mitochondria in the absence of functional NiemannPick Type C1 protein. J Lipid Res, 51, 1023-1034.

28 Fernandez, A., Llacuna, L., Fernandez-Checa, J.C. and Colell, A. (2009) Mitochondrial cholesterol loading exacerbates amyloid beta peptide-induced inflammation and neurotoxicity. The Journal of neuroscience : the official journal of the Society for Neuroscience, 29, 63946405.

29 Lim, C.Y., Davis, O.B., Shin, H.R., Zhang, J., Berdan, C.A., Jiang, X., Counihan, J.L., Ory, D.S., Nomura, D.K. and Zoncu, R. (2019) ER-lysosome contacts enable cholesterol sensing by mTORC1 and drive aberrant growth signalling in Niemann-Pick type C. Nat Cell Biol, in press.

$85630 \quad$ Liscum, L., Ruggiero, R.M. and Faust, J.R. (1989) The intracellular transport of low 857 density lipoprotein-derived cholesterol is defective in Niemann-Pick type C fibroblasts. J. Cell 858 Biol., 108, 1625-1636. 
31 Lange, Y. and Steck, T.L. (1996) The role of intracellular cholesterol transport in cholesterol homeostasis. Trends Cell Biol, 6, 205-208. 32 Chang, T.Y., Chang, C.C., Ohgami, N. and Yamauchi, Y. (2006) Cholesterol Sensing, Trafficking, and Esterification. Annu Rev Cell Dev Biol, 22, 129-157.

33 Tabas, I. (2002) Consequences of cellular cholesterol accumulation: basic concepts and physiological implications. J Clin Invest, 110, 905-911.

34 Chang, C.C., Huh, H.Y., Cadigan, K.M. and Chang, T.Y. (1993) Molecular cloning and functional expression of human acyl-coenzyme A:cholesterol acyltransferase cDNA in mutant Chinese hamster ovary cells. J Biol Chem, 268, 20747-20755. 35 Oram, J.F. and Heinecke, J.W. (2005) ATP-binding cassette transporter A1: a cell cholesterol exporter that protects against cardiovascular disease. Physiological reviews, 85, 1343-1372.

$87136 \quad$ Chang, C.C., Chen, J., Thomas, M.A., Cheng, D., Del Priore, V.A., Newton, R.S., Pape, M.E. and Chang, T.Y. (1995) Regulation and immunolocalization of acyl-coenzyme A: cholesterol acyltransferase in mammalian cells as studied with specific antibodies. J Biol Chem, 270, 29532-29540. 37 Khelef, N., Buton, X., Beatini, N., Wang, H., Meiner, V., Chang, T.Y., Farese, R.V.J., Maxfield, F.R. and Tabas, I. (1998) Immunolocalization of acyl-coenzyme A:cholesterol Oacyltransferase in macrophages. J. Biol. Chem., 273, 11218-11224. 38 Khelef, N., Soe, T.T., Quehenberger, O., Beatini, N., Tabas, I. and Maxfield, F.R. (2000) Enrichment of acyl coenzyme A:cholesterol O-acyltransferase near trans-golgi network and endocytic recycling compartment. Arterioscler. Thromb. Vasc. Biol., 20, 1769-1776.

39 Sakashita, N., Chang, C.C., Lei, X., Fujiwara, Y., Takeya, M. and Chang, T.Y. (2010) Cholesterol loading in macrophages stimulates formation of ER-derived vesicles with elevated ACAT1 activity. J Lipid Res, 51, 1263-1272.

40 Yamauchi, Y., Iwamoto, N., Rogers, M.A., Abe-Dohmae, S., Fujimoto, T., Chang, C.C.Y., Ishigami, M., Kishimoto, T., Kobayashi, T., Ueda, K. et al. (2015) Deficiency in the Lipid Exporter ABCA1 Impairs Retrograde Sterol Movement and Disrupts Sterol Sensing at the Endoplasmic Reticulum. The Journal of biological chemistry, 290, 23464-23477.

41 Mesmin, B., Pipalia, N.H., Lund, F.W., Ramlall, T.F., Sokolov, A., Eliezer, D. and Maxfield, F.R. (2011) STARD4 abundance regulates sterol transport and sensing. Mol Biol Cell, 22, 4004-4015.

42 Yamauchi, Y., Reid, P.C., Sperry, J.B., Furukawa, K., Takeya, M., Chang, C.C. and Chang, T.Y. (2007) Plasma membrane rafts complete cholesterol synthesis by participating in retrograde movement of precursor sterols. J Biol Chem, 282, 34994-35004.

43 Abi-Mosleh, L., Infante, R.E., Radhakrishnan, A., Goldstein, J.L. and Brown, M.S. (2009) Cyclodextrin overcomes deficient lysosome-to-endoplasmic reticulum transport of cholesterol in Niemann-Pick type C cells. Proceedings of the National Academy of Sciences of the United States of America, 106, 19316-19321.

44 Sandhu, J., Li, S., Fairall, L., Pfisterer, S.G., Gurnett, J.E., Xiao, X., Weston, T.A., Vashi, D., Ferrari, A., Orozco, J.L. et al. (2018) Aster Proteins Facilitate Nonvesicular Plasma Membrane to ER Cholesterol Transport in Mammalian Cells. Cell, 175, 514-529 e520. 45 Infante, R.E. and Radhakrishnan, A. (2017) Continuous transport of a small fraction of plasma membrane cholesterol to endoplasmic reticulum regulates total cellular cholesterol. Elife, 6 .

46 Maue, R.A., Burgess, R.W., Wang, B., Wooley, C.M., Seburn, K.L., Vanier, M.T., Rogers, M.A., Chang, C.C., Chang, T.Y., Harris, B.T. et al. (2012) A novel mouse model of Niemann-Pick type C disease carrying a D1005G-Npc1 mutation comparable to commonly observed human mutations. Hum Mol Genet, 21, 730-750.

47 Meiner, V.L., Cases, S., Myers, H.M., Sande, E.R., Bellosta, S., Schambelan, M., Pitas, R.E., McGuire, J., Herz, J. and Farese, R.V., Jr. (1996) Disruption of the acyl-CoA:cholesterol 
acyltransferase gene in mice: evidence suggesting multiple cholesterol esterification enzymes in mammals. Proc Natl Acad Sci U S A, 93, 14041-14046. 48 Chang, T.Y., Li, B.L., Chang, C.C. and Urano, Y. (2009) Acyl-coenzyme A:cholesterol acyltransferases. Am J Physiol Endocrinol Metab, 297, E1-9.

914 49 Lebrand, C., Corti, M., Goodson, H., Cosson, P., Cavalli, V., Mayran, N., Faure, J. and Gruenberg, J. (2002) Late endosome motility depends on lipids via the small GTPase Rab7. Embo J, 21, 1289-1300.

50 Sheff, D.R., Daro, E.A., Hull, M. and Mellman, I. (1999) The receptor recycling pathway contains two distinct populations of early endosomes with different sorting functions. J. Cell Biol., 145, 123-139.

51 Sugii, S., Reid, P.C., Ohgami, N., Du, H. and Chang, T.Y. (2003) Distinct endosomal compartments in early trafficking of low density lipoprotein-derived cholesterol. J Biol Chem, 278, 27180-27189.

52 Hulce, J.J., Cognetta, A.B., Niphakis, M.J., Tully, S.E. and Cravatt, B.F. (2013)

Proteome-wide mapping of cholesterol-interacting proteins in mammalian cells. Nat Methods, 10, 259-264.

926

53 Bock, J.B., Klumperman, J., Davanger, S. and Scheller, R.H. (1997) Syntaxin 6 functions in trans-Golgi network vesicle trafficking. Mol Biol Cell, 8, 1261-1271. 54 Orci, L., Montesano, R., Meda, P., Malaisse-Lagae, F., Brown, D., Perrelet, A. and Vassalli, P. (1981) Heterogeneous distribution of filipin--cholesterol complexes across the cisternae of the Golgi apparatus. Proc Natl Acad Sci U S A, 78, 293-297.

55 Mitchell, S.B., Iwabuchi, S., Kawano, H., Yuen, T.M.T., Koh, J.Y., Ho, K.W.D. and Harata, N.C. (2018) Structure of the Golgi apparatus is not influenced by a GAG deletion mutation in the dystonia-associated gene Tor1a. PLoS One, 13, e0206123.

56 Gleeson, P.A., Lock, J.G., Luke, M.R. and Stow, J.L. (2004) Domains of the TGN: coats, tethers and $\mathrm{G}$ proteins. Traffic, 5, 315-326.

57 Klumperman, J., Kuliawat, R., Griffith, J.M., Geuze, H.J. and Arvan, P. (1998) Mannose 6-phosphate receptors are sorted from immature secretory granules via adaptor protein AP-1, clathrin, and syntaxin 6-positive vesicles. J Cell Biol, 141, 359-371.

58 Kornfeld, S. (1992) Structure and function of the mannose 6-phosphate/insulinlike growth factor II receptors. Annu Rev Biochem, 61, 307-330.

59 Kobayashi, T., Stang, E., Fang, K.S., de Moerloose, P., Parton, R.G. and Gruenberg, J. (1998) A lipid associated with the antiphospholipid syndrome regulates endosome structure and function. Nature, 392, 193-197.

60 Ganley, I.G. and Pfeffer, S.R. (2006) Cholesterol accumulation sequesters Rab9 and disrupts late endosome function in NPC1-deficient cells. J Biol Chem, 281, 17890-17899. 61 Benes, P., Vetvicka, V. and Fusek, M. (2008) Cathepsin D--many functions of one aspartic protease. Crit Rev Oncol Hematol, 68, 12-28.

62 Auteri, J.S., Okada, A., Bochaki, V. and Dice, J.F. (1983) Regulation of intracellular protein degradation in IMR-90 human diploid fibroblasts. J Cell Physiol, 115, 167-174.

63 Pacheco, C.D., Kunkel, R. and Lieberman, A.P. (2007) Autophagy in Niemann-Pick C disease is dependent upon Beclin-1 and responsive to lipid trafficking defects. Hum Mol Genet, 16, 1495-1503.

64 Oram, J.F. (2002) ATP-binding cassette transporter A1 and cholesterol trafficking. Curr. Opin. Lipidol., 13, 373-381.

65 Venkateswaran, A., Laffitte, B.A., Joseph, S.B., Mak, P.A., Wilpitz, D.C., Edwards, P.A. and Tontonoz, P. (2000) Control of cellular cholesterol efflux by the nuclear oxysterol receptor LXR alpha. Proc Natl Acad Sci, 97, 12097-12102.

$95866 \quad$ Costet, P., Luo, Y., Wang, N. and Tall, A.R. (2000) Sterol-dependent transactivation of 959 the $A B C 1$ promoter by the liver $X$ receptor/retinoid $X$ receptor. The Journal of biological

960 chemistry, 275, 28240-28245. 
961

962

963

964

965

966

967

968

969

970

971

972

973

974

975

976

977

978

979

980

981

982

983

984

985

986

987

988

989

990

991

992

993

994

995

996

997

998

999

1000

1001

1002

1003

1004

1005

1006

1007

1008

1009

1010

1011

67 Yokoyama, S., Arakawa, R., Wu, C.-A., Iwamoto, N., Lu, R., Tsujita, M. and AbeDohmae, S. (2012) Calpain-mediated ABCA1 degradation: post-translational regulation of ABCA1 for HDL biogenesis. Biochimica et biophysica acta, 1821, 547-551.

68 Choi, H.Y., Karten, B., Chan, T., Vance, J.E., Greer, W.L., Heidenreich, R.A., Garver, W.S. and Francis, G.A. (2003) Impaired ABCA1-dependent lipid efflux and hypoalphalipoproteinemia in human Niemann-Pick type C disease. J Biol Chem, 278, 3256932577.

69 Haidar, B., Kiss, R.S., Sarov-Blat, L., Brunet, R., Harder, C., McPherson, R. and Marcel, Y.L. (2006) Cathepsin D, a lysosomal protease, regulates ABCA1-mediated lipid efflux. J Biol Chem, 281, 39971-39981.

70 Yamauchi, Y., Chang, C.C., Hayashi, M., Abe-Dohmae, S., Reid, P.C., Chang, T.Y. and Yokoyama, S. (2004) Intracellular cholesterol mobilization involved in the

ABCA1/apolipoprotein-mediated assembly of high density lipoprotein in fibroblasts. $J$ Lipid Res, 45, 1943-1951.

71 Ikenoya, M., Yoshinaka, Y., Kobayashi, H., Kawamine, K., Shibuya, K., Sato, F., Sawanobori, K., Watanabe, T. and Miyazaki, A. (2007) A selective ACAT-1 inhibitor, K-604, suppresses fatty streak lesions in fat-fed hamsters without affecting plasma cholesterol levels. Atherosclerosis, 191, 290-297.

72 Erickson, R.P., Garver, W.S., Camargo, F., Hossain, G.S. and Heidenreich, R.A. (2000) Pharmacological and genetic modifications of somatic cholesterol do not substantially alter the course of CNS disease in Niemann-Pick C mice. J Inherit Metab Dis, 23, 54-62.

73 Welch, C.L., Sun, Y., Arey, B.J., Lemaitre, V., Sharma, N., Ishibashi, M., Sayers, S., Li, R., Gorelik, A., Pleskac, N. et al. (2007) Spontaneous atherothrombosis and medial degradation in Apoe-/-, Npc1-/- mice. Circulation, 116, 2444-2452.

74 Quan, G., Xie, C., Dietschy, J.M. and Turley, S.D. (2003) Ontogenesis and regulation of cholesterol metabolism in the central nervous system of the mouse. Brain Res. Dev. Brain Res., 146, 87-98.

75 Liu, Y., Wu, Y.P., Wada, R., Neufeld, E.B., Mullin, K.A., Howard, A.C., Pentchev, P.G., Vanier, M.T., Suzuki, K. and Proia, R.L. (2000) Alleviation of neuronal ganglioside storage does not improve the clinical course of the Niemann-Pick C disease mouse. Hum. Mol. Genet., 9, 1087-1092.

76 Liu, B., Li, H., Repa, J.J., Turley, S.D. and Dietschy, J.M. (2008) Genetic variations and treatments that affect the lifespan of the NPC1 mouse. J Lipid Res, 49, 663-669.

77 Marques, A.R., Aten, J., Ottenhoff, R., van Roomen, C.P., Herrera Moro, D., Claessen, N., Vinueza Veloz, M.F., Zhou, K., Lin, Z., Mirzaian, M. et al. (2015) Reducing GBA2 Activity Ameliorates Neuropathology in Niemann-Pick Type C Mice. PLoS One, 10, e0135889.

78 Pacheco, C.D., Elrick, M.J. and Lieberman, A.P. (2009) Tau deletion exacerbates the phenotype of Niemann-Pick type $\mathrm{C}$ mice and implicates autophagy in pathogenesis. Hum $\mathrm{Mol}$ Genet, 18, 956-965.

79 Cougnoux, A., Clifford, S., Salman, A., Ng, S.L., Bertin, J. and Porter, F.D. (2018) Necroptosis inhibition as a therapy for Niemann-Pick disease, type C1: Inhibition of RIP kinases and combination therapy with 2-hydroxypropyl-beta-cyclodextrin. Mol Genet Metab, 125, 345350 .

80 Phillips, M.J. and Voeltz, G.K. (2016) Structure and function of ER membrane contact sites with other organelles. Nat Rev Mol Cell Biol, 17, 69-82.

81 Eden, E.R. (2016) The formation and function of ER-endosome membrane contact sites. Biochim Biophys Acta, 1861, 874-879.

82 Ridgway, N.D. and Zhao, K. (2018) Cholesterol transfer at endosomal-organelle membrane contact sites. Curr Opin Lipidol, 29, 212-217.

83 Luo, J., Jiang, L.Y., Yang, H. and Song, B.L. (2019) Intracellular Cholesterol Transport by Sterol Transfer Proteins at Membrane Contact Sites. Trends Biochem Sci, 44, 273-292. 

generated by the hydrolysis of cytoplasmic cholesteryl ester and transported to the plasma membrane. Atherosclerosis, 146, 309-319.

1015 85 Kellner-Weibel, G., Luke, S.J. and Rothblat, G.H. (2003) Cytotoxic cellular cholesterol is selectively removed by apoA-I via ABCA1. Atherosclerosis, 171, 235-243. ACAT1/SOAT1 in microglia stimulates autophagy-mediated lysosomal proteolysis and increases Abeta1-42 clearance. J Neurosci, 34, 14484-14501. 87 Huang, L.H., Melton, E.M., Li, H., Sohn, P., Jung, D., Tsai, C.Y., Ma, T., Sano, H., Ha, H., Friedline, R.H. et al. (2018) Myeloid-specific Acat1 ablation attenuates inflammatory responses in macrophages, improves insulin sensitivity, and suppresses diet-induced obesity. Am J Physiol Endocrinol Metab, 315, E340-E356.

102488 Accad, M., Smith, S.J., Newland, D.L., Sanan, D.A., King, L.E., Jr., Linton, M.F., Fazio, S. and Farese, R.V., Jr. (2000) Massive xanthomatosis and altered composition of atherosclerotic lesions in hyperlipidemic mice lacking acyl CoA:cholesterol acyltransferase $1 . J$ Clin Invest, 105, 711-719.

102889 Yagyu, H., Kitamine, T., Osuga, J., Tozawa, R., Chen, Z., Kaji, Y., Oka, T., Perrey, S., 1029 Tamura, Y., Ohashi, K. et al. (2000) Absence of ACAT-1 attenuates atherosclerosis but causes 1030 dry eye and cutaneous xanthomatosis in mice with congenital hyperlipidemia. J Biol Chem, 275, 1031 21324-21330.

103290 Huang, L.H., Gui, J., Artinger, E., Craig, R., Berwin, B.L., Ernst, P.A., Chang, C.C. and proliferation in bone marrow and causes leukocytosis. Arterioscler Thromb Vasc Biol, 33, 20812087.

91 Bryleva, E.Y., Rogers, M.A., Chang, C.C., Buen, F., Harris, B.T., Rousselet, E., Seidah, N.G., Oddo, S., LaFerla, F.M., Spencer, T.A. et al. (2010) ACAT1 gene ablation increases 24(S)-hydroxycholesterol content in the brain and ameliorates amyloid pathology in mice with AD. Proc Natl Acad Sci U S A, 107, 3081-3086.

92 Saleheen, D., Natarajan, P., Armean, I.M., Zhao, W., Rasheed, A., Khetarpal, S.A., Won, H.H., Karczewski, K.J., O'Donnell-Luria, A.H., Samocha, K.E. et al. (2017) Human knockouts and phenotypic analysis in a cohort with a high rate of consanguinity. Nature, 544, 235-239.

93 Huang, L.H., Melton, E.M., Li, H., Sohn, P., Rogers, M.A., Mulligan-Kehoe, M.J., Fiering, S.N., Hickey, W.F., Chang, C.C. and Chang, T.Y. (2016) Myeloid Acyl-CoA:Cholesterol Acyltransferase 1 Deficiency Reduces Lesion Macrophage Content and Suppresses Atherosclerosis Progression. J Biol Chem, 291, 6232-6244.

94 Melton, E.M., Li, H., Benson, J., Sohn, P., Huang, L.H., Song, B.L., Li, B.L., Chang, C.C.Y. and Chang, T.Y. (2019) Myeloid Acat1/Soat1 KO attenuates pro-inflammatory responses in macrophages and protects against atherosclerosis in a model of advanced lesions. The Journal of biological chemistry, in press.

95 Huang, L.H., Melton, E.M., Li, H., Sohn, P., Jung, D., Tsai, C.Y., Ma, T., Sano, H., Ha, H., Friedline, R.H. et al. (2018) Myeloid-specific Acat1 ablation attenuates inflammatory responses in macrophages, improves insulin sensitivity, and suppresses diet-induced obesity. American journal of physiology. Endocrinology and metabolism, in press.

96 Li, J., Gu, D., Lee, S.S., Song, B., Bandyopadhyay, S., Chen, S., Konieczny, S.F., Ratliff, T.L., Liu, X., Xie, J. et al. (2016) Abrogating cholesterol esterification suppresses growth and metastasis of pancreatic cancer. Oncogene, in press.

105997 Jiang, Y., Sun, A., Zhao, Y., Ying, W., Sun, H., Yang, X., Xing, B., Sun, W., Ren, L., Hu, 1060 B. et al. (2019) Proteomics identifies new therapeutic targets of early-stage hepatocellular 1061 carcinoma. Nature, 567, 257-261. 
106298 Yang, W., Bai, Y., Xiong, Y., Zhang, J., Chen, S., Zheng, X., Meng, X., Li, L., Wang, J., $1063 \mathrm{Xu}, \mathrm{C}$. et al. (2016) Potentiating the antitumour response of CD8(+) T cells by modulating 1064 cholesterol metabolism. Nature, 531, 651-655.

106599 Chin, J. and Chang, T.Y. (1981) Evidence for coordinate expression of 3-hydroxy-31066 methylglutaryl coenzyme A reductase ad low density lipoprotein binding activity. J Biol Chem, 1067 256, 6304-6310.

1068100 Bascunan-Castillo, E.C., Erickson, R.P., Howison, C.M., Hunter, R.J., Heidenreich, R.H., 1069 Hicks, C., Trouard, T.P. and Gillies, R.J. (2004) Tamoxifen and vitamin E treatments delay 1070 symptoms in the mouse model of Niemann-Pick C. J Appl Genet, 45, 461-467.

1071101 Willnow, T.E. and Herz, J. (1994) Genetic deficiency in low density lipoprotein receptor1072 related protein confers cellular resistance to Pseudomonas exotoxin A. Evidence that this 1073 protein is required for uptake and degradation of multiple ligands. J Cell Sci, 107 ( Pt 3), 7191074726.

1075102 Limanek, J.S., Chin, J. and Chang, T.Y. (1978) Mammalian cell mutant requiring 1076 cholesterol and unsaturated fatty acid for growth. Proc Natl Acad Sci U S A, 75, 5452-5456.

1077103 Chang, C.C., Doolittle, G.M. and Chang, T.Y. (1986) Cycloheximide sensitivity in 1078 regulation of acyl coenzyme A:cholesterol acyltransferase activity in Chinese hamster ovary 1079 cells. 1. Effect of exogenous sterols. Biochemistry, 25, 1693-1699.

1080104 Sugii, S., Reid, P.C., Ohgami, N., Shimada, Y., Maue, R.A., Ninomiya, H., Ohno1081 Iwashita, Y. and Chang, T.Y. (2003) Biotinylated theta-toxin derivative as a probe to examine 1082 intracellular cholesterol-rich domains in normal and Niemann-Pick type C1 cells. J Lipid Res, 44, 1083 1033-1041.

1084

1085

1086

1087

1088

1089

1090

1091

1092

1093

\section{Abbreviations}

ABCA1: ATP- binding cassette protein A1; ACAT/SOAT: Acyl-coezyme A:cholesterol

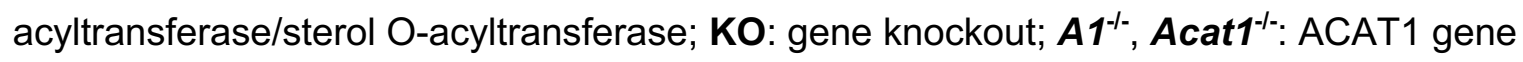
ablation; CD-M6PR: cation-dependent mannose-6-phosphate receptors; ER: endoplasmic reticulum; PM: plasma membrane; TGN: trans-Golgi network; LE: late endosomes; LXRs: liver

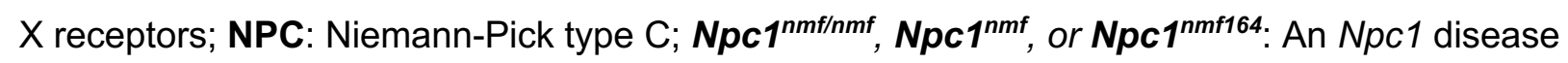
mouse model with D1005G mutation; NPA: Niemann-Pick type A. 
$1 \mathrm{~A}$

1B
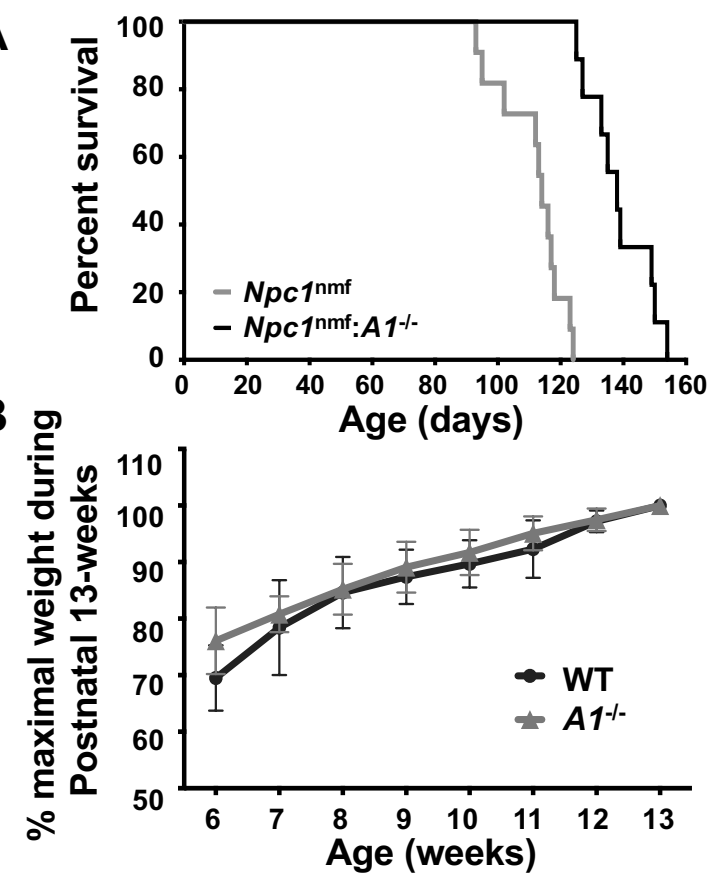
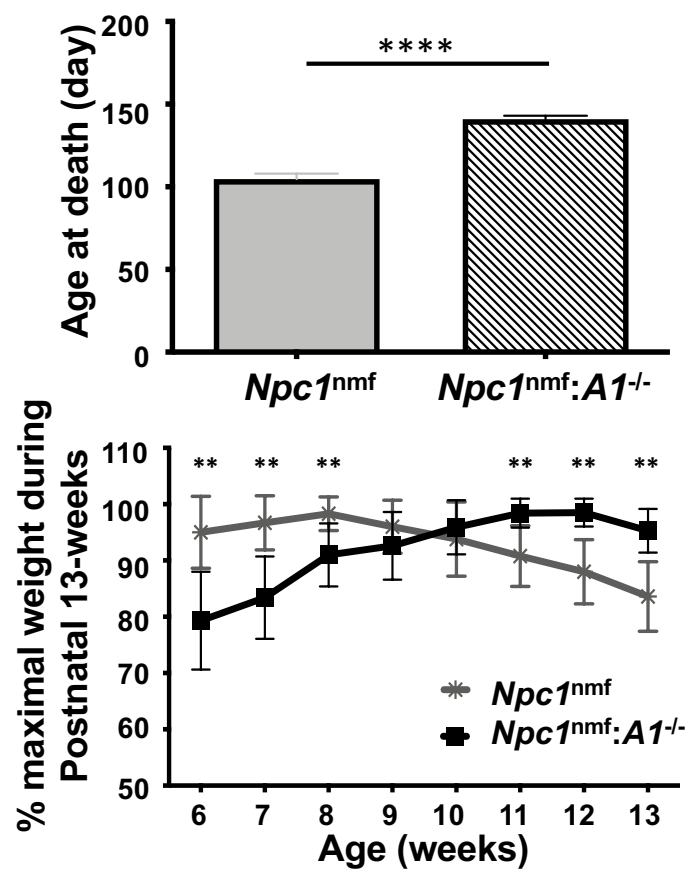

Fig. 1. Effect of $A 1^{-1 /}$ on the life span and weight loss of $N p c 1^{\text {nmf }}$ mice.

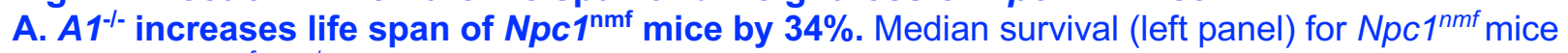
and for $N p c 1^{1 m f}: A 1^{-1-}$ mice is 113 days and 138 days respectively. Mean survival (right panel) is 102 days and 137 days, respectively. $\mathrm{N}=18$ mice for $N p c 1^{1 m f}$ and $\mathrm{N}=16$ for $N p c 1^{1 \mathrm{mf}}: A 1^{-1-}$ mice. Equal numbers of male and female mice were used, and the procedure described in (46) was adopted to define death of the $N p c 1^{1 m f}$ mouse. The $p$-value for survival curves is $<0.0001$.

B. A $1^{-1-}$ delays weight loss of $N p c 1^{n m f}$ mice (right panel) but not WT mice (left panel). Weight measurement began at 6 weeks of age. Data are expressed as percent maximum weight during the first 13 weeks. $\mathrm{N}=10$ mice per group with equal numbers of males and females evaluated. Error bars indicate $1 \mathrm{SEM}$. In the right panel, except for weeks $9(p=0.2)$ and $10(p=0.4)$, the $p$-value for each week is $<0.003$. In the left panels, there are no significant differences. 
2A

\section{P80 Liver Histology}

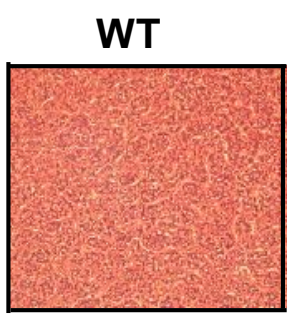

Npc $1^{\text {nmf }}$

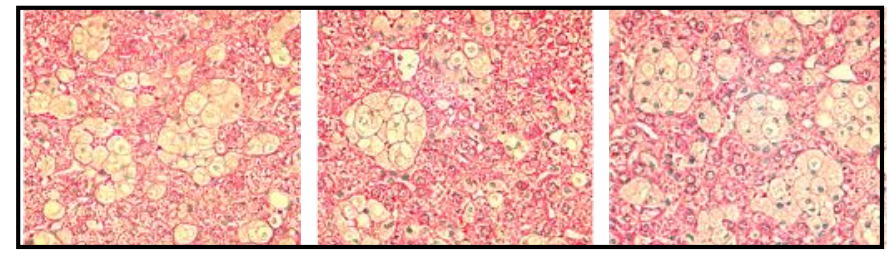

A1/-

Npc1 ${ }^{\mathrm{nmf}}: A 1^{-/-}$
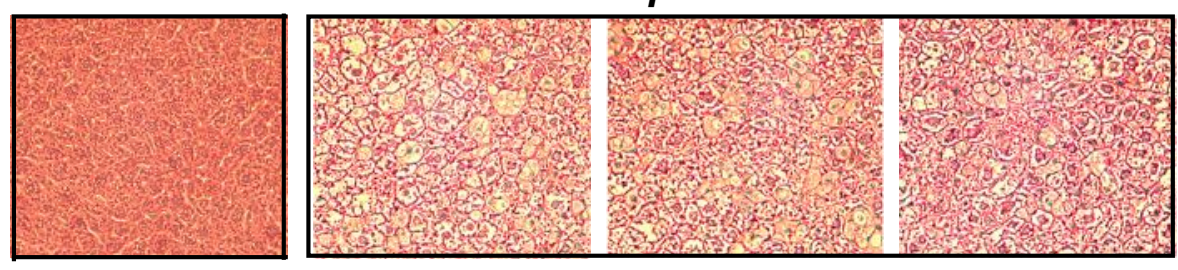

2B

P80 Spleen Histology
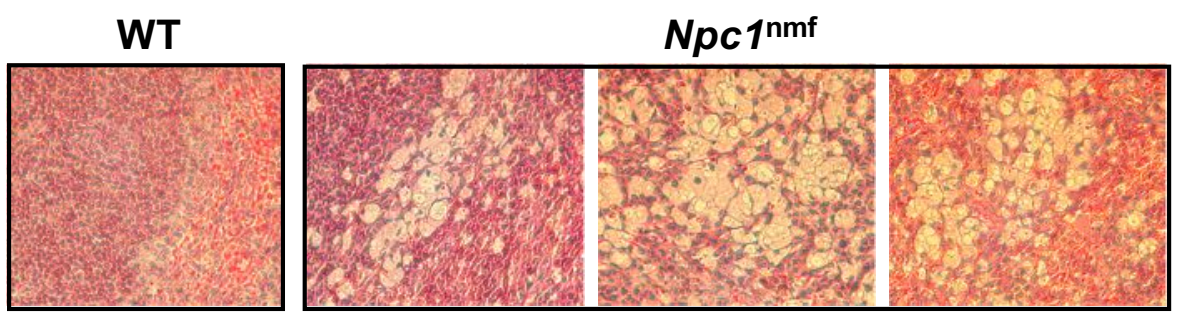

A1\%

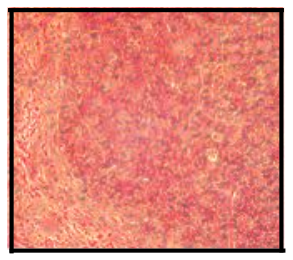

Npc1 ${ }^{\mathrm{nmf}}: A 1^{-/-}$

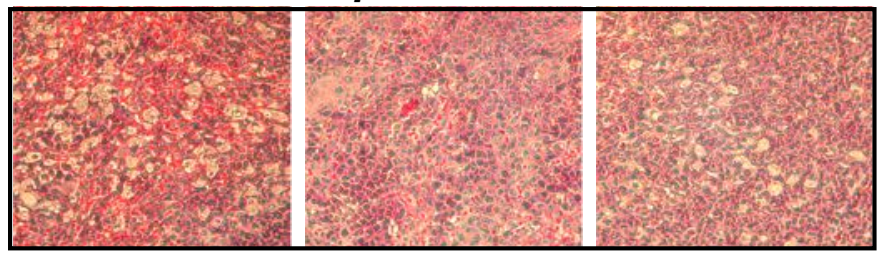


2C

\section{P80 Lung Histology}

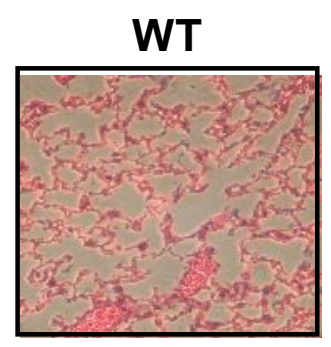

A1

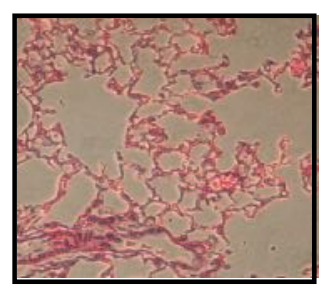

Npc1 $1^{\text {mf }}$

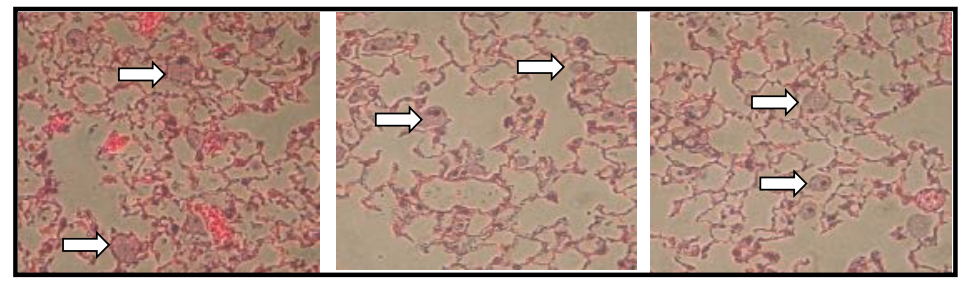

Npc1 ${ }^{\text {nmf }}: A 1^{-/-}$

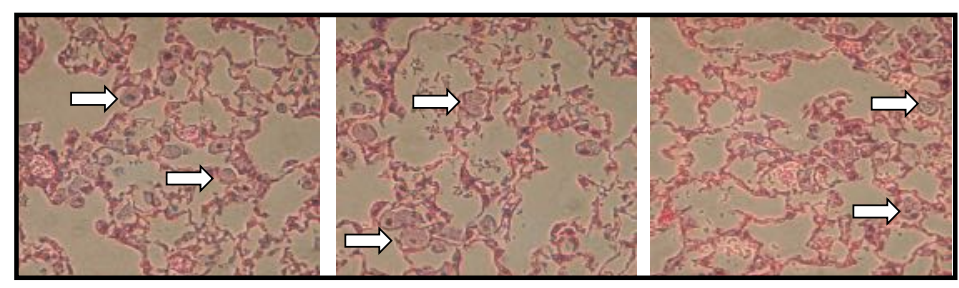

2D

P80 Cerebellum Histology

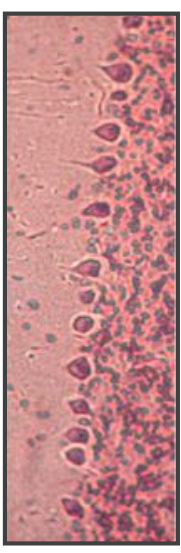

WT

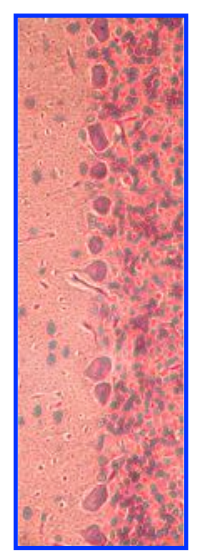

A1 $1-$

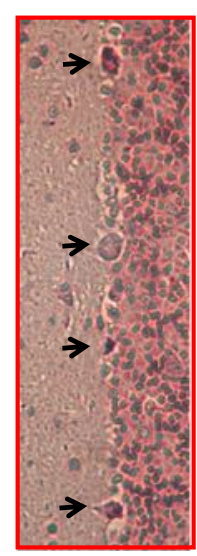

Npc1 ${ }^{\text {nmf }}$

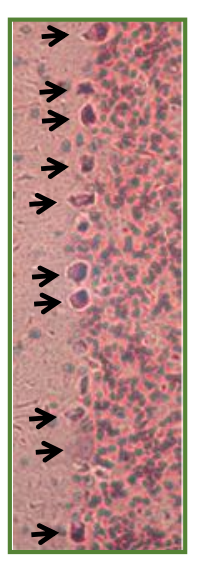

Npc1 ${ }^{\text {nmf }}: A 1^{\%}$
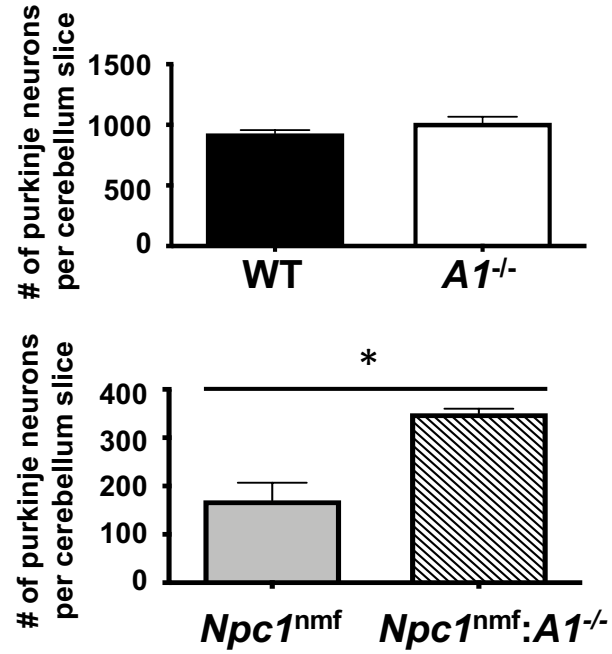
A P50 Mouse Cerebellum

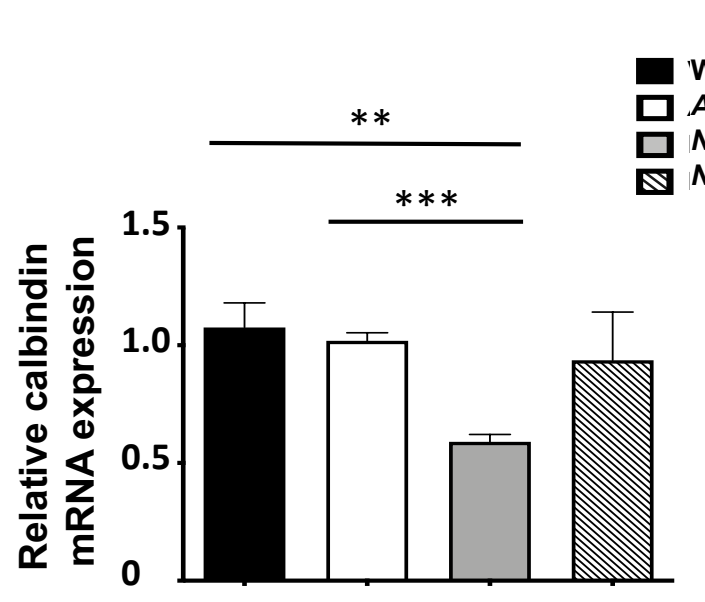

$2 F$

\section{Rotarod Test}

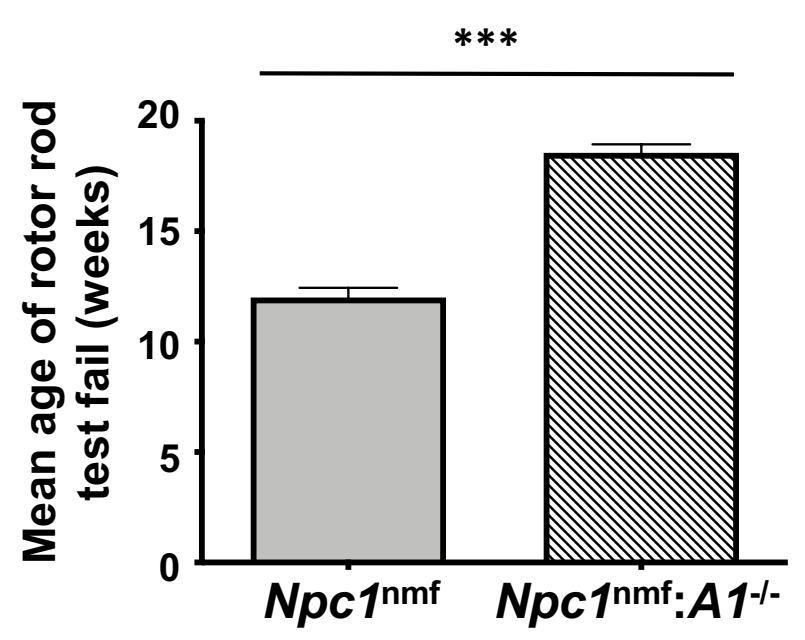

B P90 Mouse Cerebellum

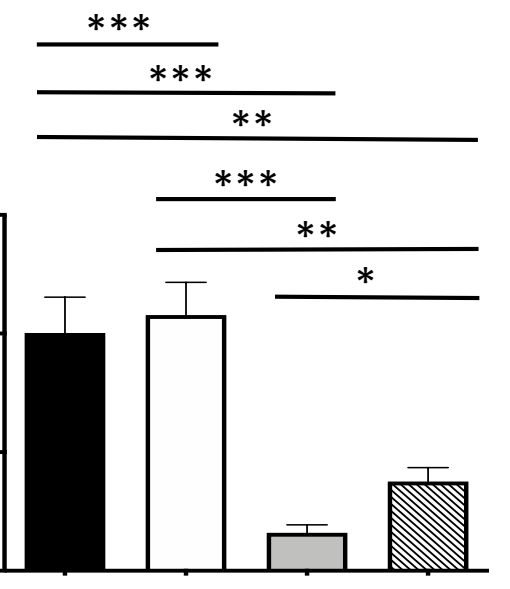
number of Purkinje neurons in each case. The relative number of Purkinje neurons (indicated by arrows in the images) was quantitated by counting in two separate cerebellar lobes. $N=2$ to 4 animals per group. Error bars indicate 1 SEM. For the right bottom panel, $p<0.05$.

E. $A 1^{-/-}$reduces the loss of calbindin expression in $N p c 1^{n m f}$ mouse cerebellum without affecting calbindin expression in WT mouse cerebellum. Cerebellar tissue was isolated from the brains of P50 (left panel) and P90 mice (right panel) and calbindin mRNA levels were measured by RT-PCR, with GAPDH also measured for normalization. Tissues were collected from 3 mice of each genotype. F. $A 1^{-/-}$prevents the decline in motor skill in the $N p c 1^{n m f}$ mouse. Mice were tested each week in 3 consecutive trials on a rod rotating at a constant speed $(24 \mathrm{rpm})$ for up to $90 \mathrm{~s}$ per trial. The fail time was defined as the age at which the mouse failed to stay on the rod at least 10 s during one of the 3 trials or froze on the rotarod and did not move. $\mathrm{N}=13$ mice for $N p c 1^{\mathrm{nmf}}$ and $\mathrm{N}=11$ mice for $N p c 1^{n m f}: A 1^{-/-}$. Comparable numbers of male and female mice were evaluated. The $p$-value is $<0.001$. 

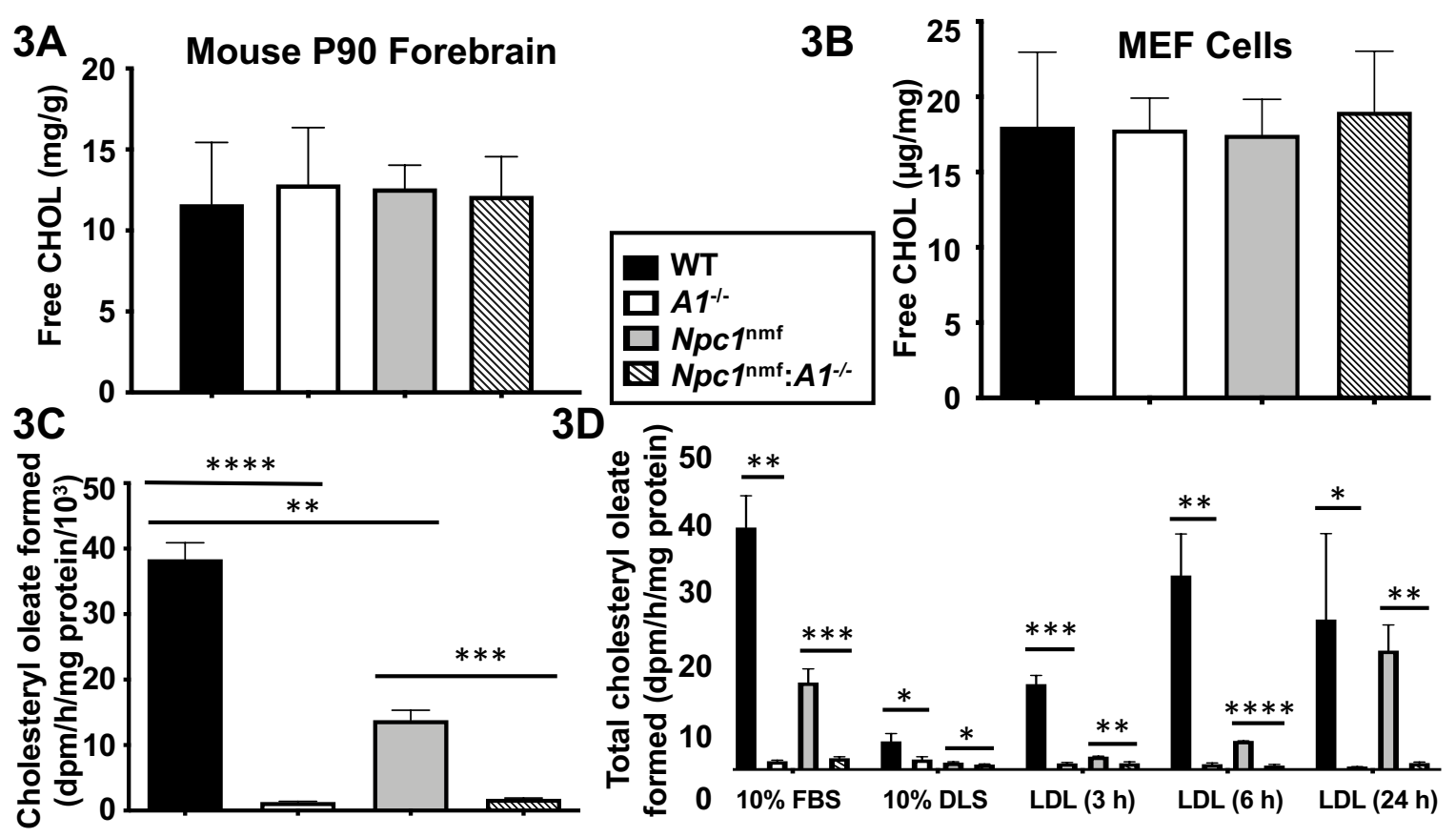

Fig. 3. Cholesterol content and cholesteryl ester biosynthesis.

A. Free cholesterol content in P90 WT, $A 1^{-/}, N p c 1^{\mathrm{nmf}}$, and $N p c 1^{\mathrm{nmf}}: A 1^{-/-}$mouse forebrain. Tissues were homogenized in chloroform: methanol 2:1, filtered by Whatman filter paper, dried under nitrogen then resuspended in methanol. Free cholesterol content was determined in triplicate by using Wako's Free Cholesterol E kit. $\mathrm{N}=5$ mice ( 3 male and 2 female) per group. Error bars indicate 1 SEM.

B. Free cholesterol content in mouse embryonic fibroblasts (MEFs). MEF were seeded in 6well dishes at 200,000 cells/well and grown in DMEM plus 10\% serum to near confluence. After three washes with PBS, cells were scraped off the dish to form suspensions in PBS and were used for protein measurement and lipid extraction by chloroform/methanol. Cholesterol content was determined as described in part A above. Data shown is from 3 platings per genotype.

C. Cholesteryl ester biosynthesis in MEFs continuously grown in lipoprotein containing medium. Cells were grown as described in part B above. Cholesteryl ester biosynthesis in intact cells was described in (103). Data shown is from 3 platings per genotype.

D. Cholesterol ester biosynthesis in MEFs grown in cholesterol containing medium (10\% FBS), cholesterol free medium (10\% DLS), or 10\% DLS in response to LDL feeding for 3 h, $\mathbf{6}$ h, or $\mathbf{2 4} \mathrm{h}$. Human LDL and delipidated fetal bovine serum were prepared as described (103). 


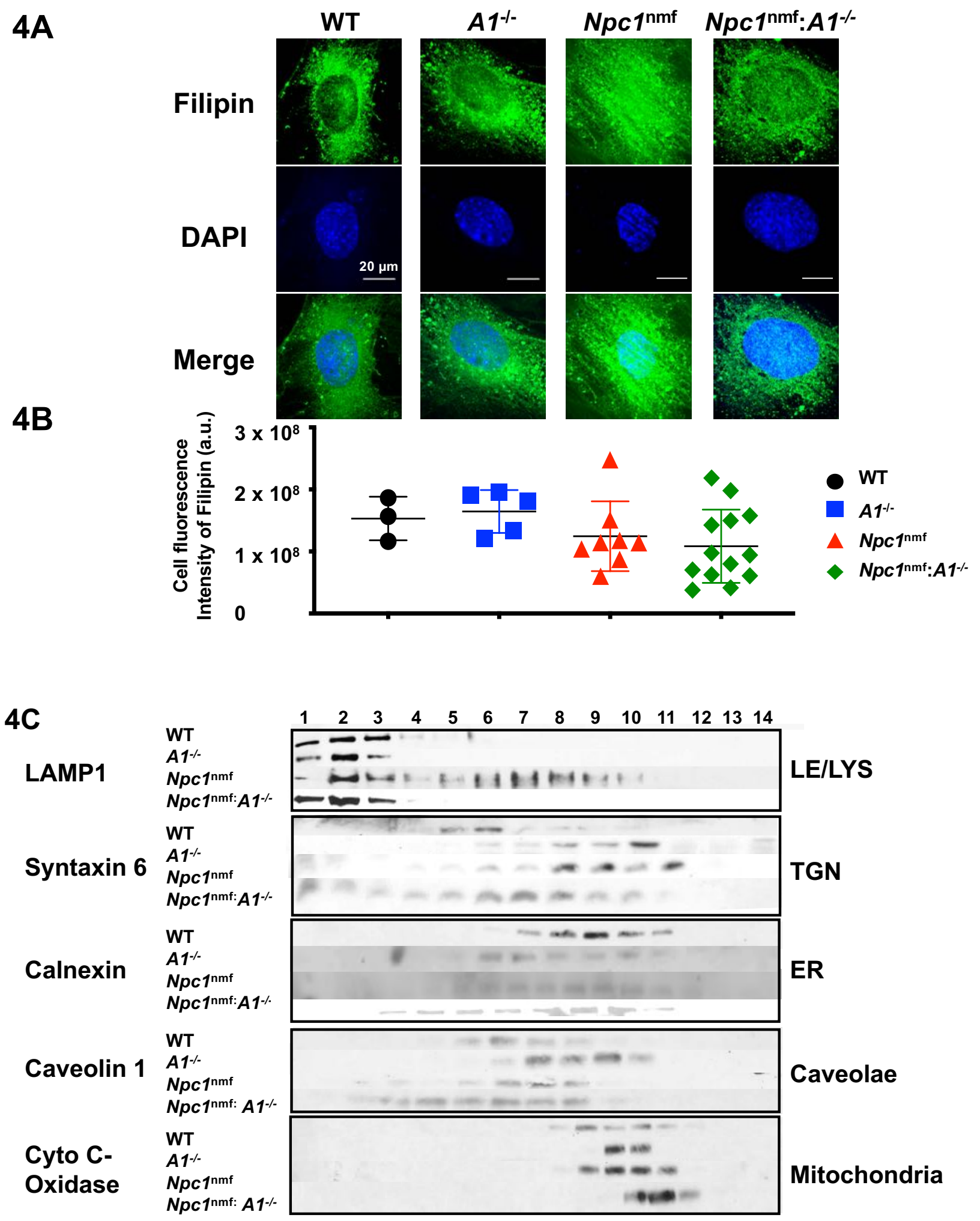



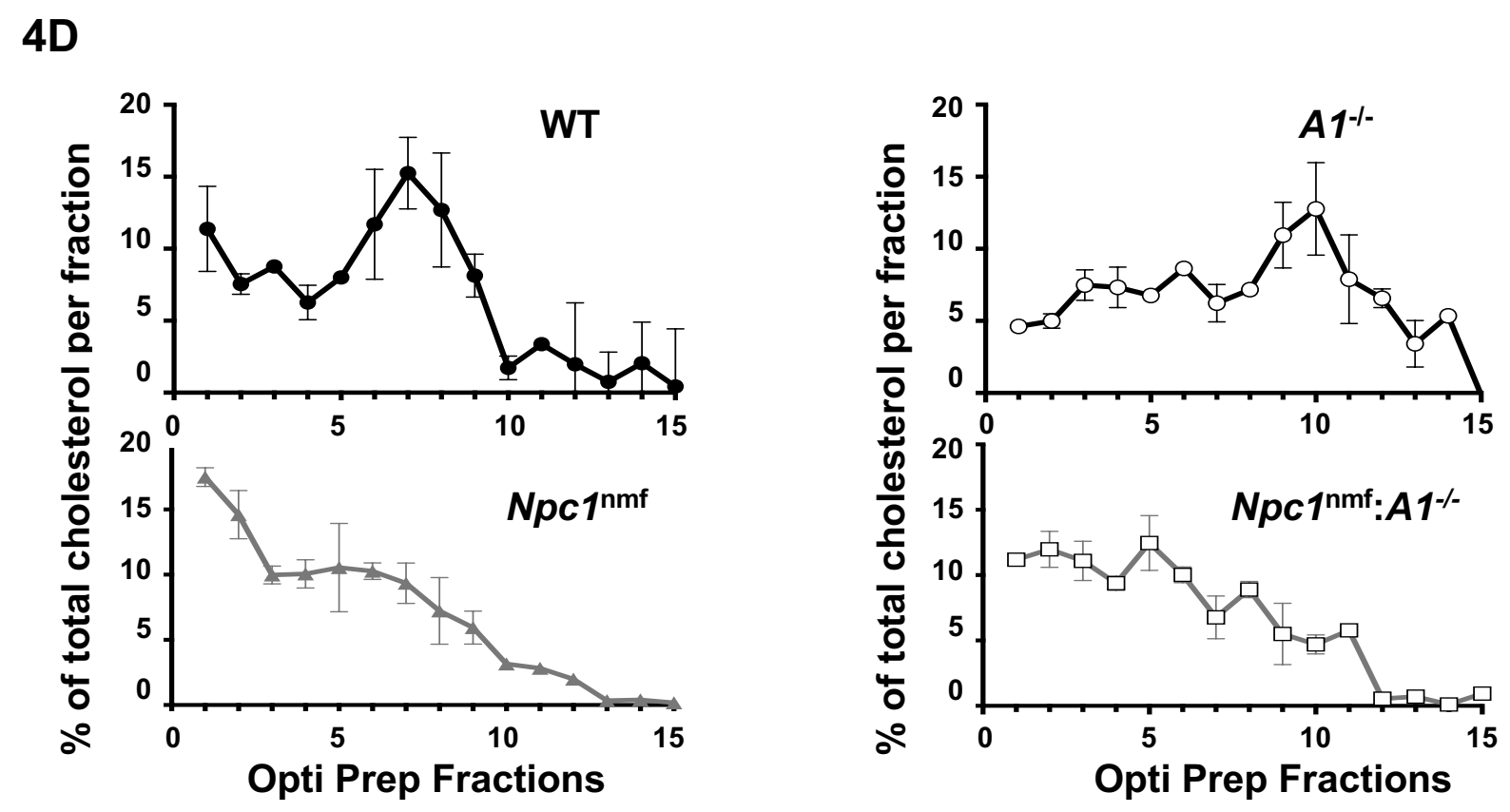

Fig. 4. Cholesterol distribution in mouse embryonic fibroblasts (MEFs).

A. MEFs from WT, $A 1^{-/-}, N p c 1^{\mathrm{nmf}}$, and $N p c 1^{\mathrm{nmf}}: A 1^{-/-}$mice were seeded on poly-d-lysine treated glass coverslips in 12-well plates. Filipin staining was carried out according to (104).

B. Total fluorescence intensity per cell. Fluorescence was quantified using NIH Image J. Each point represents the value obtained for an individual cell.

C. Localization of subcellular organelles after cell fractionation. Antibodies for specific protein markers (listed on far left) were used to localize specific organelles (listed on right).

D. Cholesterol distribution in various subcellular organelles. For each cell type, cells from a single $15-\mathrm{cm}$ dish were grown in medium plus $10 \%$ serum until confluent. Cell homogenization and OptiPrep density gradient ultracentrifugation, were carried out as described (22). Fourteen fractions were collected from each sample, with each fraction analyzed in triplicate for cholesterol content using a Wako kit. The values reported are normalized to the total cholesterol content present in all fractions. Data are means +/- 1 SD from 2 separate experiments. 

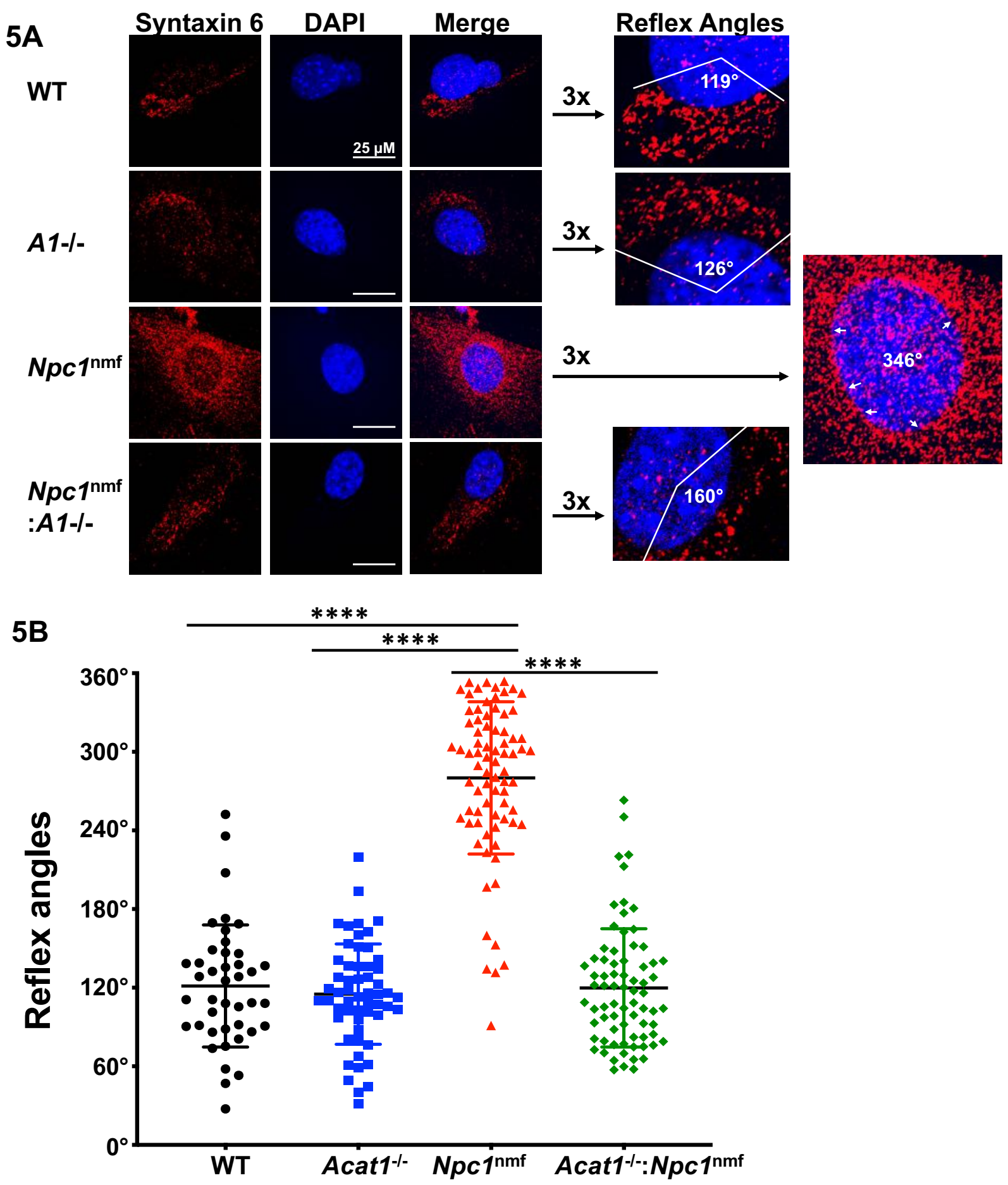
5C
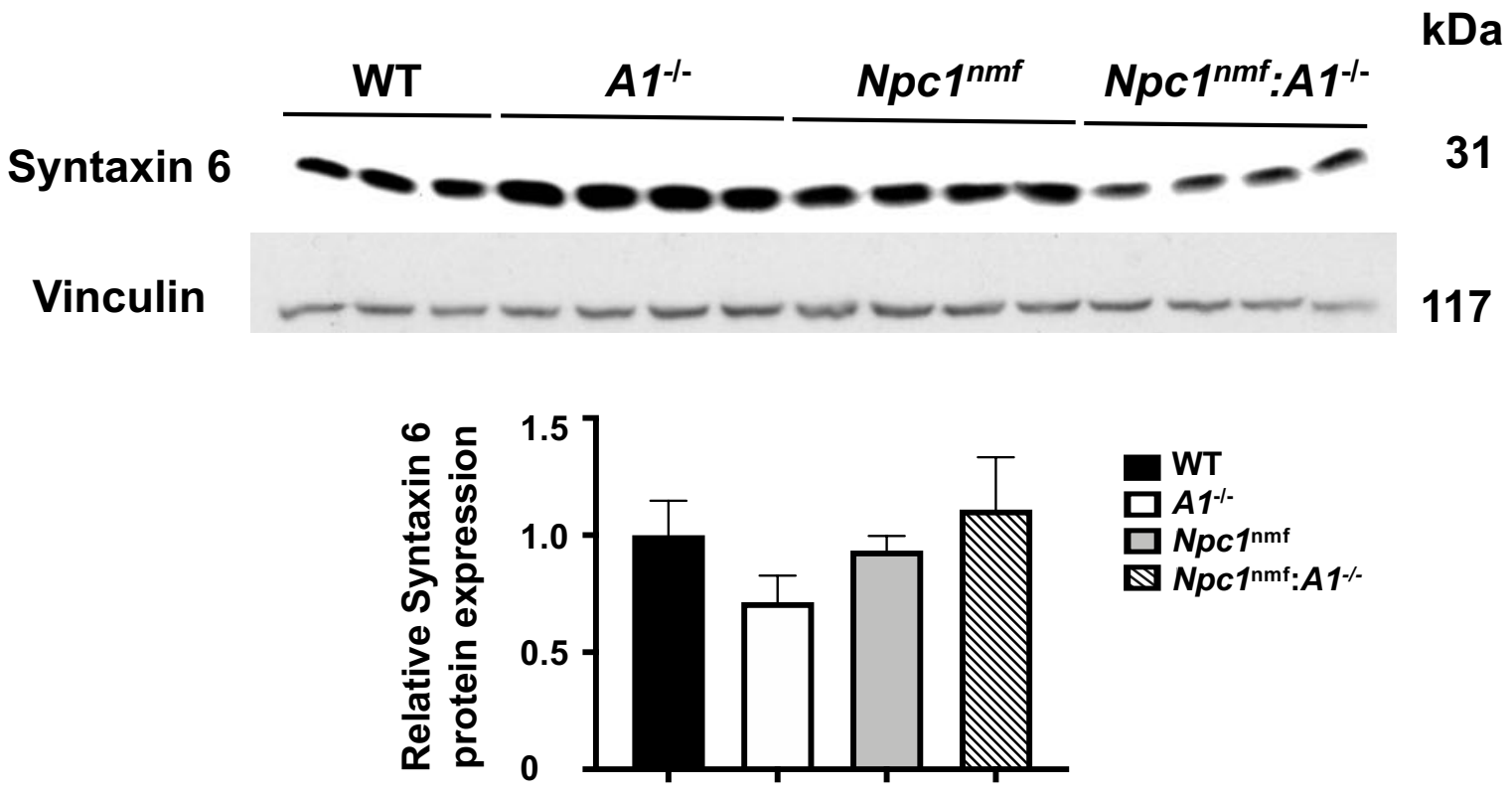

5D

WT

$A 1^{-/-}$
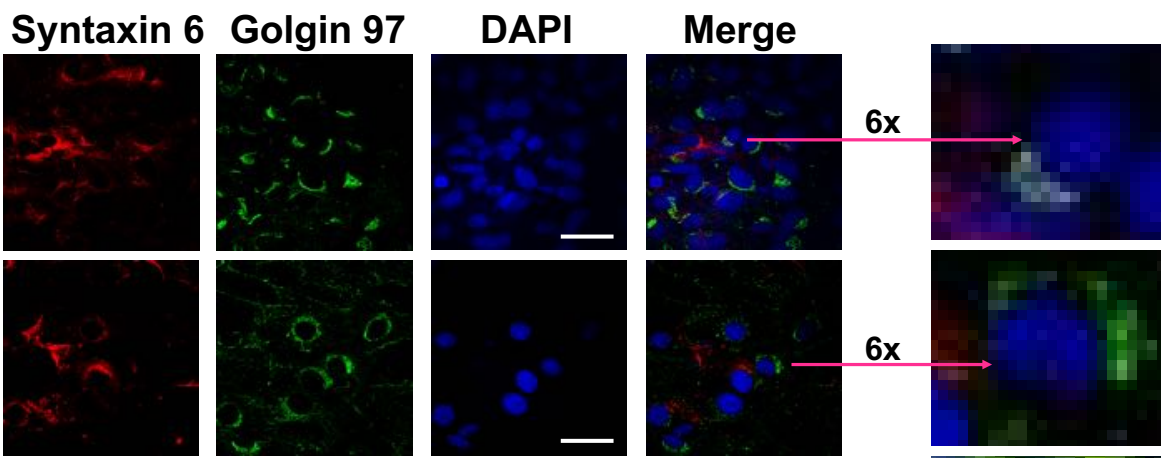

Npc1 $1^{\mathrm{nmf}}$
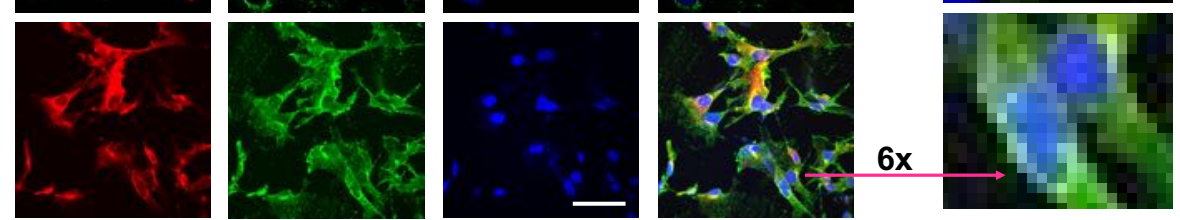

Npc1 ${ }^{\text {nmf }}: A 1^{-1-}$
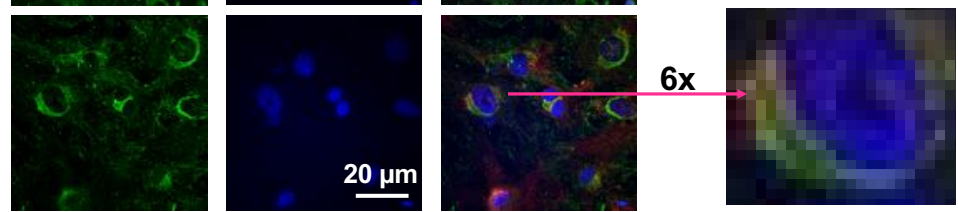
$5 \mathrm{E}$

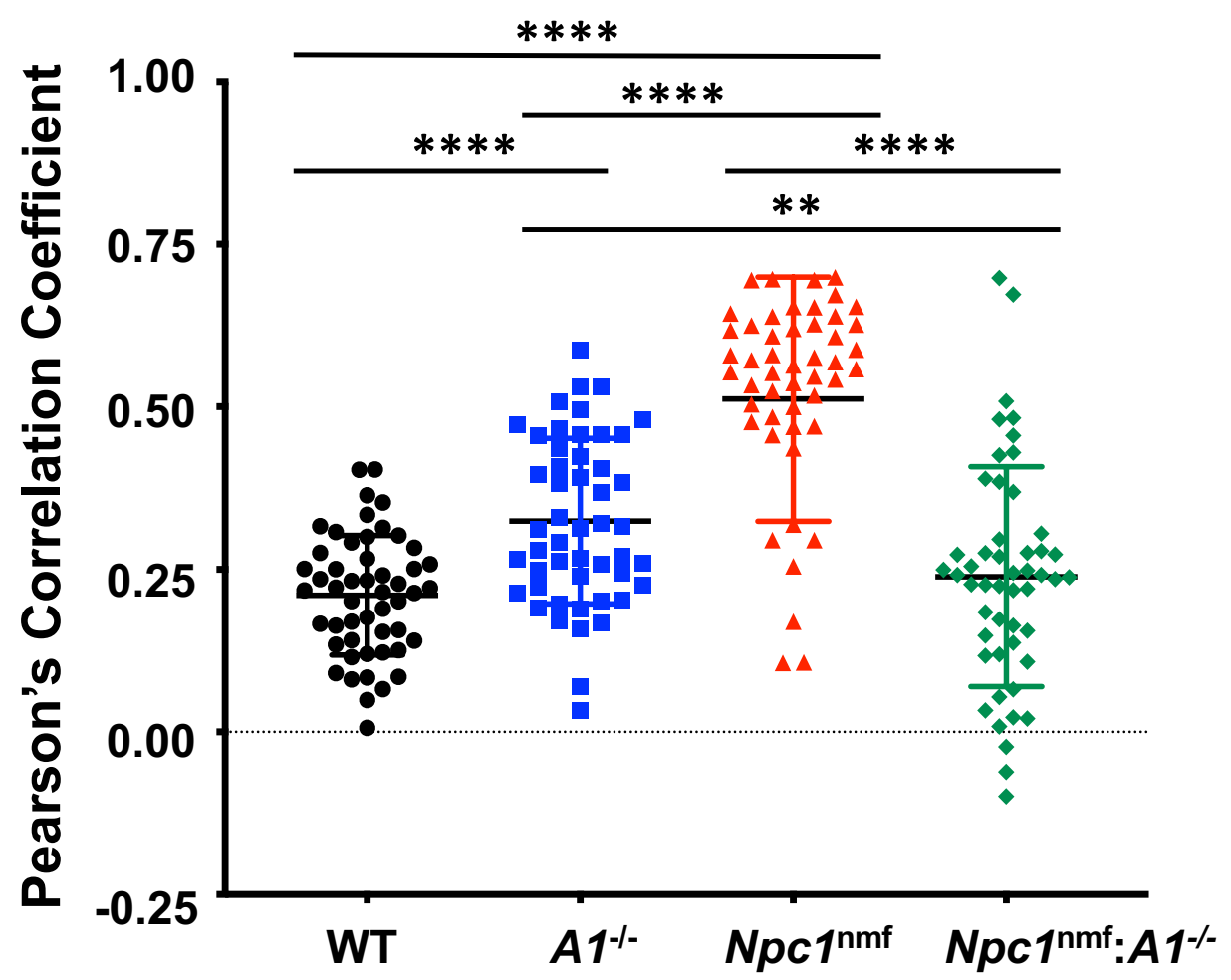

Fig. 5. Localization of syntaxin 6 and golgin 97 in intact mouse embryonic fibroblasts (MEFs).

A. The methods used for the detection of fluorescence-labeled syntaxin 6 in MEFs are described in the Methods. Fiji-ImageJ software was used to calculate the "Reflex angle", which is indicated in the images on the right.

B. The Reflex Angle of individual cells from WT, $A 1^{-/-}, N p c 1^{\mathrm{nmf}}$, and $N p c 1^{\mathrm{nmf}}: A 1^{-/-}$mice. Between 50 to 70 cells were measured for each genotype.

C. Relative syntaxin 6 protein content in lysates of MEFs. Cells were seeded in $60 \mathrm{~mm}$ culture dishes and grown in DMEM plus $10 \%$ serum until confluent. Then $200 \mu \mathrm{l}$ of $10 \%$ SDS were added per dish, and $150 \mathrm{\mu g}$ of the solubilized protein was loaded per lane for Western blot analyses. The vinculin signal was used as the loading control. Error bars indicate 1 SEM.

D. Double immunofluorescence of syntaxin 6 and golgin 97 in fixed, intact MEFs. The conditions used were the same as described in part A above.

E. Degree of apparent colocalization between syntaxin 6 and golgin 97 in MEFs. Nikon NISElement AR Imaging Software was used to create the Maximum Intensity Projection used to calculate the degree of colocalization, which is reported as Pearson's correlation coefficient. Each data point represents the result from an individual cell, and images from more than 50 cells were collected for each genotype. GraphPad Prism's One-way ANOVA multiple comparisons method was used for statistical analysis. 
$6 A$

\begin{tabular}{|c|c|c|c|c|}
\hline & WT & $A 1^{-/-}$ & Npc1nmf & Npc1nmf: $A 1^{-/-}$ \\
\hline
\end{tabular}

Vinculin

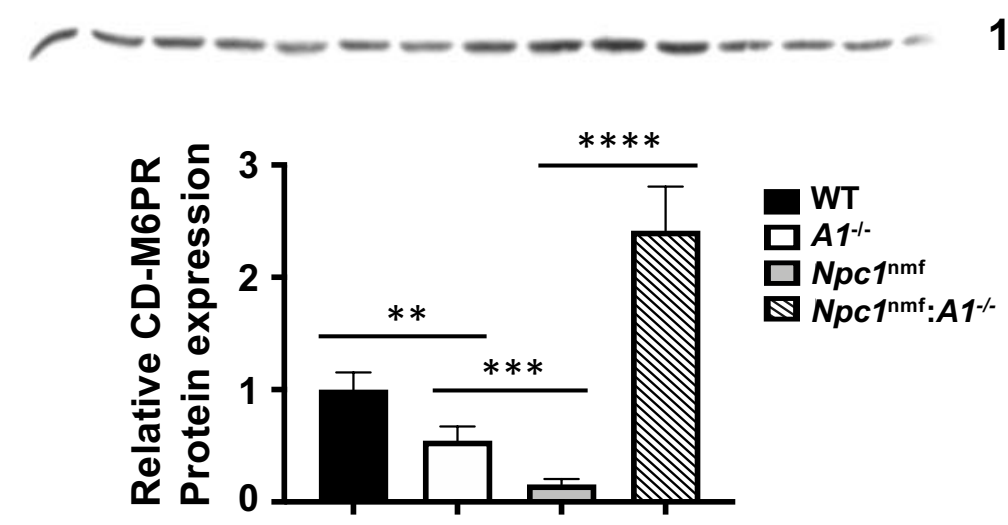

6B

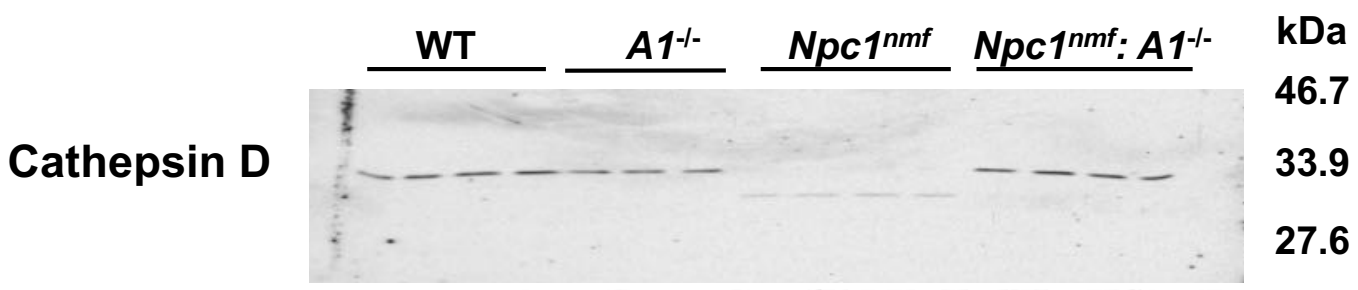

Vinculin

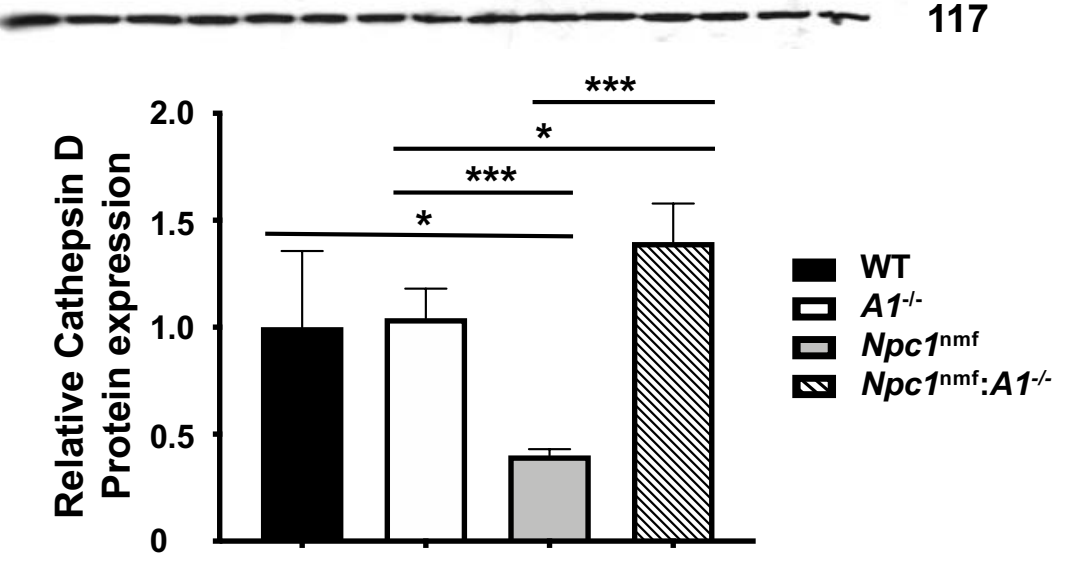




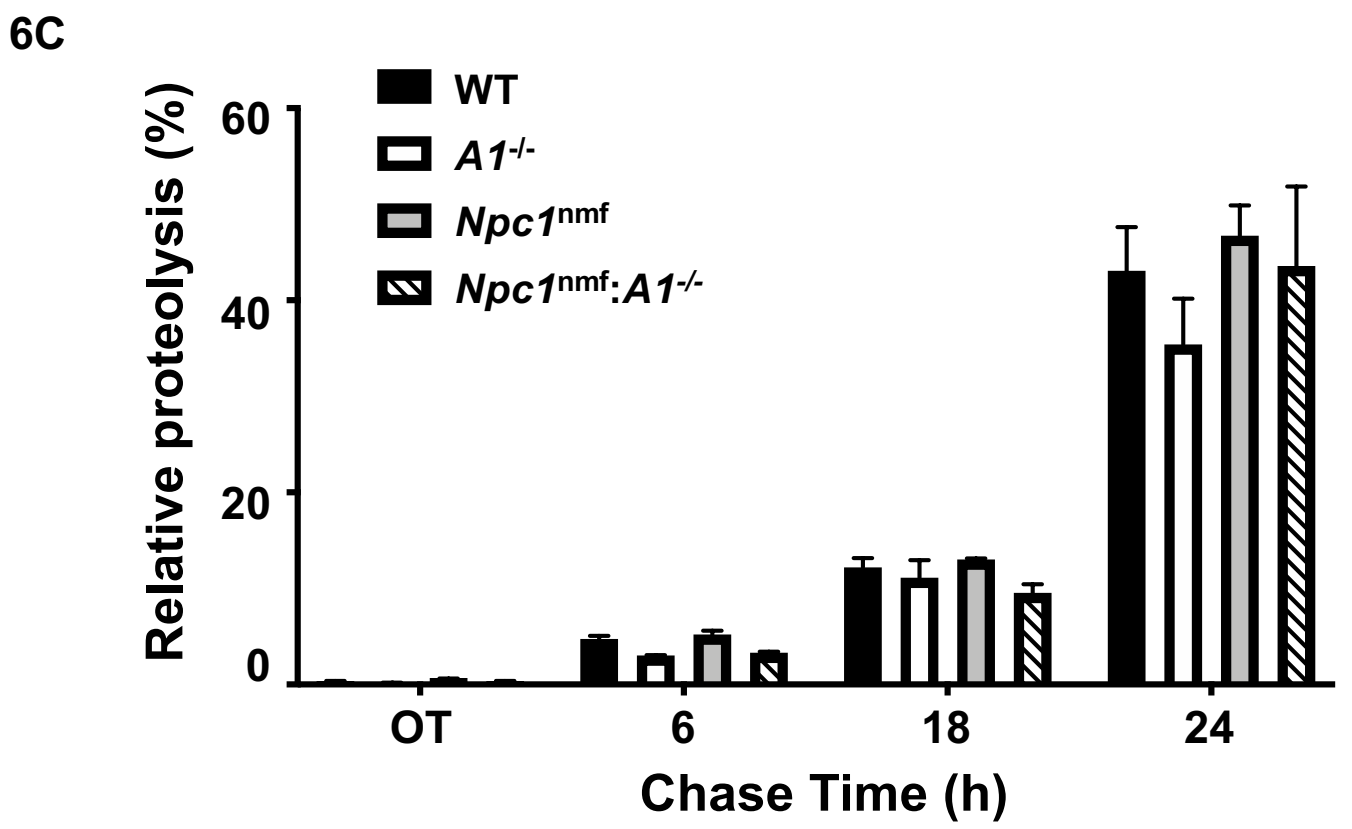

Fig 6. Analyses of various protein content and degradation of long-lived proteins in mouse embryonic fibroblasts (MEFs) from WT, $A 1^{-/}, \mathrm{Npc} 1^{n m f}$, and $\mathrm{Npc1^{nmf }}: A 1^{-/}$mice. For parts $A$ and $B$, the cell growth conditions were the same as described in Fig. $5 \mathrm{C}$. Vinculin signal was used as the loading control.

A. The relative contents of CD-M6PR protein (46-kDa) in MEFs.

B. The relative contents of cathepsin D protein (heavy chain of the mature enzyme) (30 to 32-kDa in WT, $A 1^{-/}$, and $N p c 1^{n m f}: A 1^{-/-}$cells. And $28-\mathrm{kDa}$ in $N p c 1^{n m f}$ cells).

C. The degradation of long-lived proteins in MEFs from WT, $A 1^{-/}, N p c 1^{n m f}$, and $N p c 1^{n m f}: A 1^{-/}$. The analysis of protein degradation was conducted as described in the Method. Results are reported as relative proteolysis (\%). Error bars indicate 1 SEM.

7A

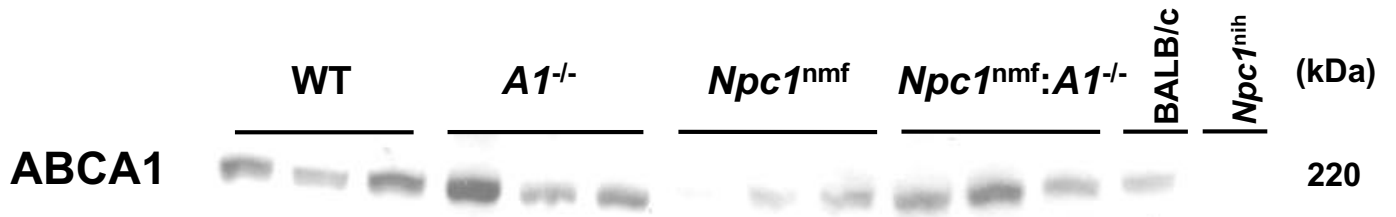
NPC1

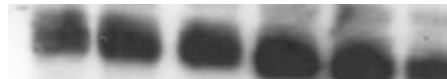

Vinculin
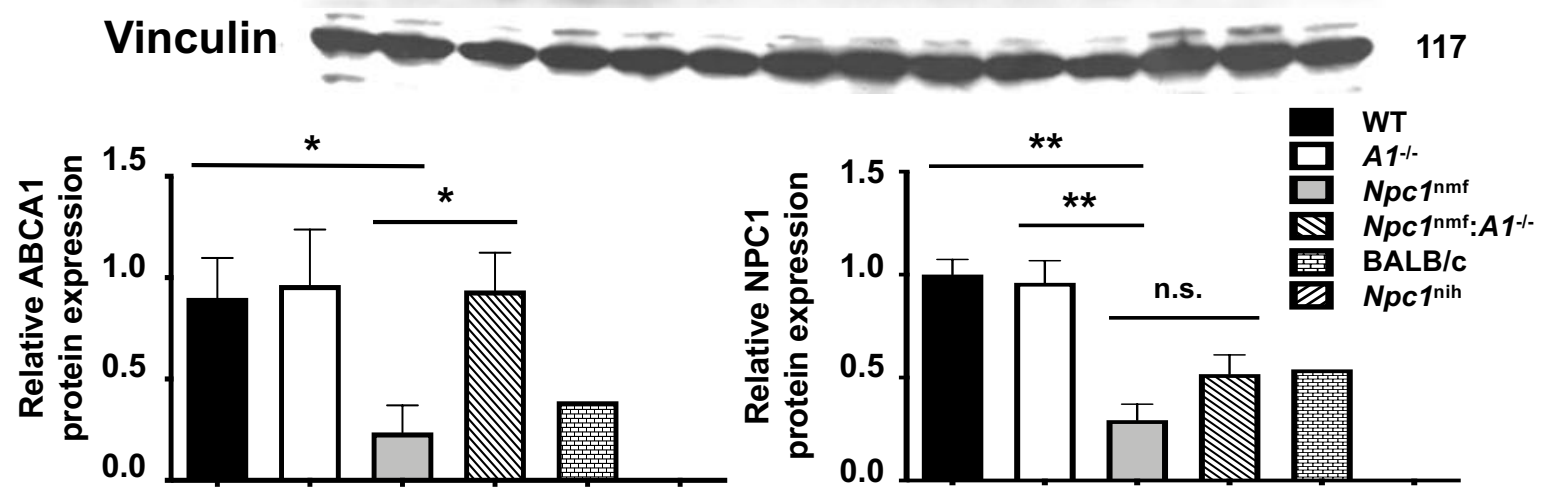
7B
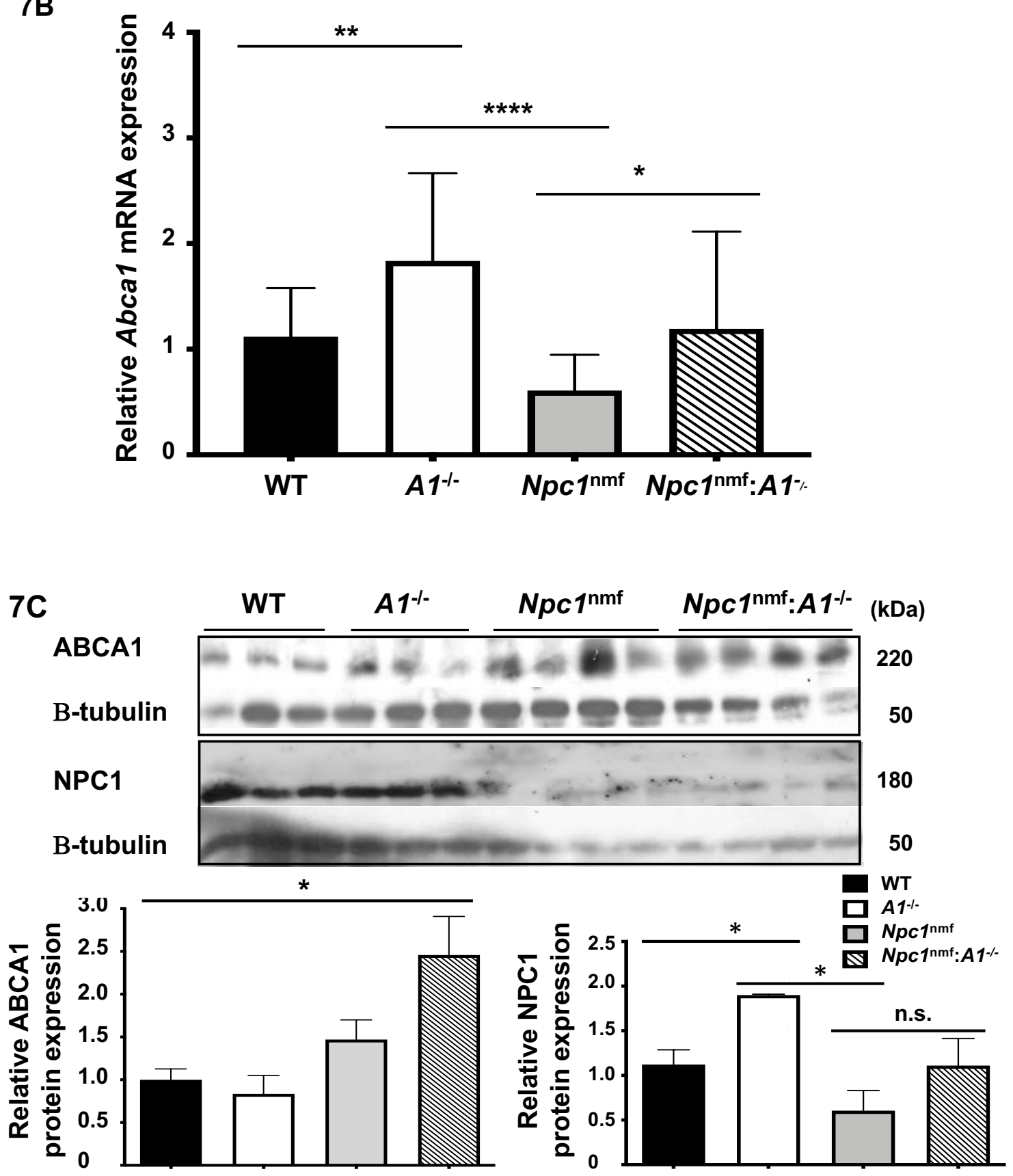
7D

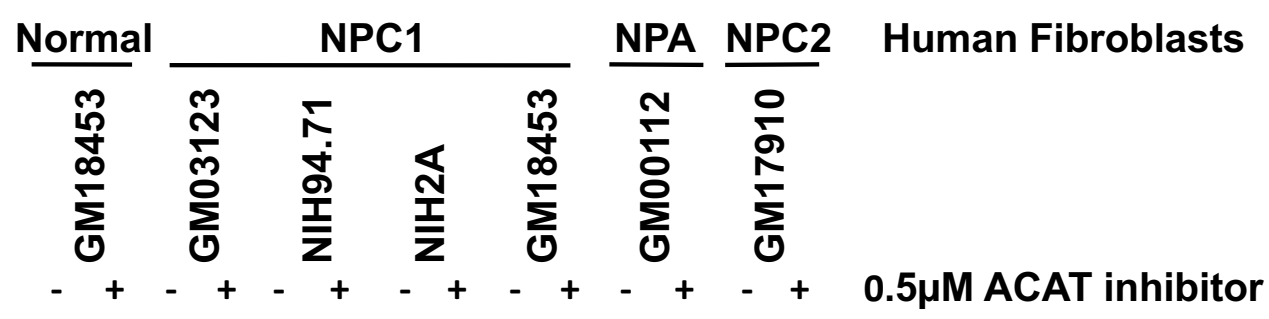

ABCA1

(light exposure)

ABCA1

(longer exposure)

Vinculin

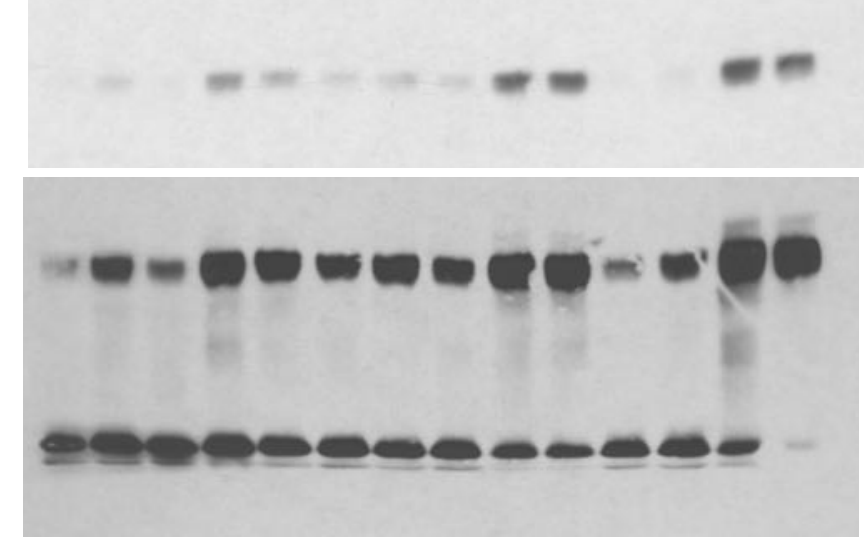

$220(\mathrm{kDa})$

7E

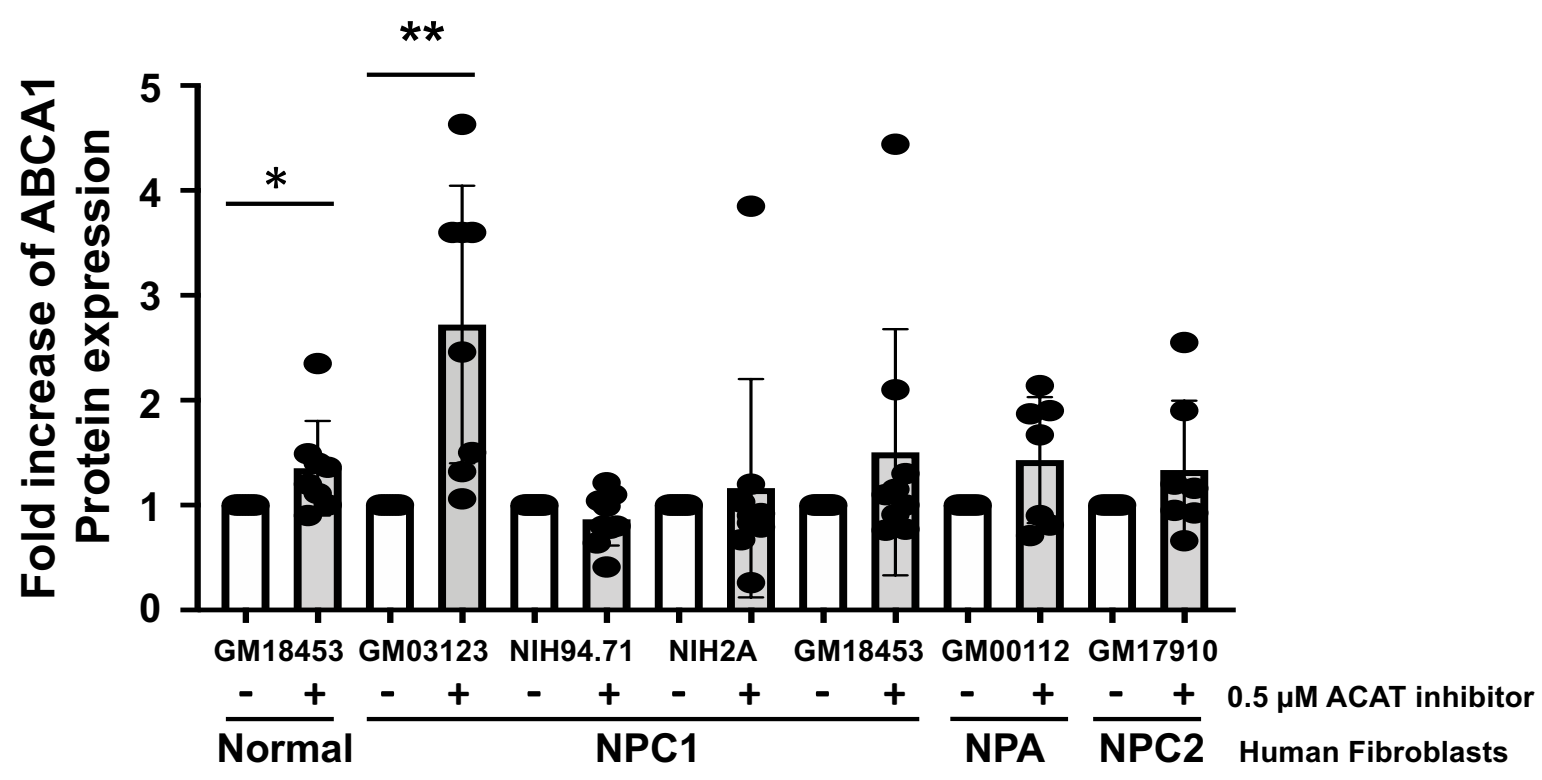

Fig. 7. ABC1 and NPC1 expression in WT, $A 1^{-1-}, N p c 1^{\mathrm{nmf}}$, and $N p c 1^{\mathrm{nmf}}: A 1^{-1 /}$ cells and tissues.

For parts A, B, and D, the cell growth conditions were the same as described in Fig. 5C.

For parts $A, B$, and $C$, cells and tissues from all four genotypes of mice (WT, $A 1^{-1}, N p c 1^{\mathrm{nmf}}$, and $\left.N p c 1^{\mathrm{nmf}}: A 1^{1-1}\right)$ were analyzed.

A. Expression of ABCA1 (220 kDa) and NPC1 (180 kDa) proteins in MEFs.

B. Expression of Abca1 mRNA in MEFs. 
C. Expression of ABCA1 and NPC1 proteins in P80 mouse cerebellum. Tissues were prepared as described in Methods. $p<0.05^{*}$, n.s., not significant.

D. Expression of ABCA1 protein in human fibroblasts (Hfs). The vinculin signal was used as the loading control.

E. Relative expression of ABCA1 protein in human fibroblasts (Hfs) cultured in the presence or absence of $0.5 \mu \mathrm{M}$ of ACAT inhibitor K604. 